\title{
Smoking initiation: Peers and personality
}

\author{
Chin-Sheng Hsieh \\ Department of Economics, Chinese University of Hong Kong \\ HANS VAN KIPPERSLUIS \\ Erasmus School of Economics, Erasmus University Rotterdam and Tinbergen Institute
}

\begin{abstract}
Social interactions are widely recognized to play an important role in smoking initiation among adolescents. In this paper, we hypothesize that emotionally stable, conscientious individuals are better able to resist peer pressure in the uptake of smoking. We exploit detailed friendship nominations in the US Add Health data, and extend the Spatial Autoregressive (SAR) model to deal with (i) endogenous peer selection, and (ii) unobserved contextual effects, in order to identify heterogeneity in peer effects with respect to personality. The results indicate that peer effects in the uptake of smoking are predominantly affecting individuals who are emotionally unstable. That is, emotionally unstable individuals are more vulnerable to peer pressure. This finding not only helps understanding heterogeneity in peer effects, but additionally provides a promising mechanism through which personality affects later life health and socioeconomic outcomes.
\end{abstract}

KEYWORDs. Smoking, peer effects, personality, SAR model, Bayesian MCMC.

JEL CLASSIFICATION. C11, C21, I12.

\section{INTRODUCTION}

Although smoking rates have fallen over past decades, recently this trend has stalled (DHHS (2012)) and smoking continues to be the leading preventable cause of death, killing nearly 6 million people each year (Mokdad, Marks, Stroup, and Gerberding (2004), Danaei, Ding, Mozaffarian, Taylor, Rehm, Murray, and Ezzati (2009), OECD (2013)). Reliably identifying the causal factors underlying youth smoking initiation is vital to develop effective smoking prevention programs (Heckman, Flyer, and Loughlin (2008)). The economics literature has traditionally focused on price, taxation, and addiction as determinants of smoking (Chaloupka and Warner (2000), DeCicca, Kenkel, and Mathios (2002)),

Chih-Sheng Hsieh: cshsieh@cuhk . edu.hk

Hans van Kippersluis: hvankippersluis@ese .eur.nl

Hsieh thanks the Hong Kong Research Grants Council (ECS grant 24613115) for financial support. Van Kippersluis thanks the Netherlands Organization of Scientific Research (NWO Veni grant 016.145.082) and the National Institute on Aging of the National Institutes of Health (R01AG037398) for financial support. Part of this work was completed while Hans van Kippersluis was a visiting scholar at Chinese University of Hong Kong. The authors are grateful to the coeditor, three anonymous referees, seminar participants at Erasmus University Rotterdam, the National Graduate Institute for Policy Studies (GRIPS) Tokyo, Academia Sinica, National Taiwan University, University of Mainz, University of Lugano, and Baptist University of Hong Kong for helpful comments.

(c) 2018 The Authors. Licensed under the Creative Commons Attribution-NonCommercial License 4.0. Available at http://qeconomics.org. https://doi.org/10.3982/QE615 
yet in recent years considerably more attention is paid to social interactions in smoking and other unhealthy behaviors (DeCicca, Kenkel, Mathios, Shin, and Lim (2008), Cawley and Ruhm (2011)). This is not surprising as social interactions and peer effects are not just often-cited determinants of smoking initiation, but—when present-additionally capable of generating social multiplier effects of policy interventions (Cutler and Glaeser (2010), Fletcher (2010), Cawley and Ruhm (2011)).

This paper is to the best of our knowledge the first to investigate whether peer influences are moderated by personality. In particular, we intend to answer the question: Are individuals who are emotionally stable and conscientious less vulnerable to peer pressure in the uptake of smoking? The paper contributes to two distinct lines of thriving literatures.

First, we contribute to the literature on the effects of personality on health behavior and health. It is strongly established that personality traits such as conscientiousness and emotional stability are linked to healthy behavior and health (Borghans, Duckworth, Heckman, and ter Weel (2008), Almlund, Duckworth, Heckman, and Kautz (2011)). In fact, improving personality traits is one of the key mechanisms through which early childhood interventions have long-lasting effects on life outcomes (Heckman, Pinto, and Savelyev (2013), Campbell, Conti, Heckman, Moon, Pinto, Pungello, and Pan (2014)). Nonetheless, the reason for the relationship between personality and health is poorly understood (Almlund et al. (2011), Young and Beaujean (2011)). Here, we investigate whether adolescents who are more conscientious and emotionally stable are less susceptible to peer influences, and better able to resist pressure from bad role models. If true, this could provide an important mechanism through which personality affects later life health.

Second, we make two contributions to the literature on the identification and interpretation of peer effects. Although the importance of peer effects in smoking is now widely recognized (Chaloupka and Warner (2000), Heckman, Flyer, and Loughlin (2008), Cawley and Ruhm (2011)), implicitly homogenous effects are typically assumed (see Section 2.1 for a review). This implies that we know strikingly little about which adolescents are most likely to join in versus avoid the deviant behavior that is present to some degree in almost all adolescent peer groups (Allen, Chango, Szwedo, Schad, and Marston (2012)). Our first contribution to the peer effects literature is to improve understanding of heterogeneity in social interactions with respect to personality. The second contribution, which we explain in more detail below, is to introduce a Spatial Autoregressive (SAR) model that can simultaneously deal with (i) endogenous selection of friends, and (ii) unobserved contextual effects, in the identification of endogenous peer effects. This methodological extension overcomes the problem of disentangling the endogenous peer effect from unobserved contextual effects (see, e.g., Fruehwirth (2014)), and at the same time addresses the problem of endogenous friendship formation (Goldsmith-Pinkham and Imbens (2013), Hsieh and Lee (2016), Badev (2017)).

Identifying peer effects is notoriously plagued with two major identification problems (Manski (1993), Moffitt (2001), Graham (2015)): (i) the reflection problem that plagues linear peer effect models, and (ii) correlated effects. The reflection problem 
arises because the peers' observed outcome is the result of the peers' background (Sacerdote (2011)), and hence it is difficult to distinguish between endogenous effects (the individual's behavior is directly affected by peers' behavior) and contextual effects (the individual's behavior is affected by the characteristics of his/her peers). The second problem, correlated effects, is due to selection (e.g., parents choose schools for their children; students select friends on the basis of same gender, race, etc.) or due to sharing common environments (e.g., same teachers). Hence, it is difficult to separate peer effects from spurious correlations in behavior due to common characteristics and environments.

Although the use of randomization in identifying peer effects is gaining popularity (e.g., Sacerdote (2001), Zimmerman (2003), Eisenberg, Golberstein, and Whitlock (2014)), and has recently been vociferously advocated (Angrist (2014)), randomization has two fundamental limitations specific to the peer effects literature. First, whereas randomization is the ideal approach to tackle correlated effects, it does not solve the reflection problem. Indeed, Sacerdote (2001) and Carrell, Sacerdote, and West (2013) used randomly assigned roommates in colleges, yet could not distinguish between endogenous and contextual peer effects. Second, it is extremely difficult, if not impossible, to exogenously manipulate an individual's peer group. After all, if you are randomly assigned a roommate in college that you do not like, then you are unlikely to spend time with the roommate, and the peer effects in such settings may be very different from the peer effect in naturally occurring settings (Card and Giuliano (2013)). Indeed, Carrell, Sacerdote, and West (2013) report that randomly assigned Air Force Academy students segregated into homogeneous subgroups, which illustrates the sheer difficulty of randomly manipulating peer groups.

In contrast to randomization, the SAR model is able to tackle the reflection problem by exploiting information of friendship networks to separate endogenous effects and contextual effects (Bramoullé, Djebbari, and Fortin (2009), Lee, Liu, and Lin (2010), Lin (2010)). The intuition is that since peer groups are not completely overlapping, one can use the characteristics of the nonoverlapping friends of your friends as instrumental variables for the outcome of your friends. This approach however has two main limitations. First, relying on friendship nominations aggravates the problem of correlated effects. After all, a selected group of nominated friends is highly likely to share common characteristics and environments. Second, although the SAR model is technically able to separate endogenous peer effects from contextual effects, the endogenous peer effect will still be biased in case of unobserved contextual effects (e.g., Arcidiacono, Foster, Goodpaster, and Kinsler (2012), Fruehwirth (2014)).

We follow Goldsmith-Pinkham and Imbens (2013) and Hsieh and Lee (2016) by using a SAR model that accounts for peer group fixed effects (to account for similar environments), and the endogenous selection of friends (to account for individual correlated effects). We do so by explicitly modeling the friendship formation using observed and unobserved (latent) factors influencing both the selection of friends and smoking initiation. ${ }^{1}$ Our approach goes beyond Goldsmith-Pinkham and Imbens (2013) and Hsieh and Lee (2016) in two ways.

\footnotetext{
${ }^{1} \mathrm{An}$ alternative is to use the whole classroom as the relevant peer group. This could take away worries about endogenous network formation, and the variation in group sizes can still identify peer effects (Lee
} 
First, we move from a model with homogenous peer effects to a model that allows peer effects to be heterogeneous, depending on a possibly endogenous individual characteristic (in our case personality). We present models that (i) stratify the sample into personality subgroups, (ii) include linear interaction terms between the peer effect and personality, and (iii) allow personality to be endogenously determined. These alternative approaches provide a template for researchers aiming to study heterogeneous peer effects in a SAR model, where the source of heterogeneity is potentially endogenous.

Second, our model allows not just for observed contextual effects (observed friend's characteristics) influencing the individual's outcome, but additionally for unobserved contextual effects. This is important since any omitted contextual effect will be picked up by the endogenous peer effect (see, e.g., Fruehwirth (2014)). ${ }^{2}$ Our approach allows disentangling endogenous peer effects (one student's smoking behavior affects another student's smoking behavior) from unobserved contextual effects (e.g., one student's risk preferences affect another student's smoking behavior). We use various specification checks to gauge the potential of our approach, and present evidence that our selectioncorrected SAR (SC-SAR) model is able to deal with some of the most notorious and persistent problems in identifying the endogenous peer effect.

Our SC-SAR estimates are based upon the Add-Health data, which has three main advantages. First, Add-Health provides detailed friendship nominations that enable not just solving the reflection problem, but additionally identifying the most relevant peer group. Second, the data contains personality measures for conscientiousness and emotional stability, both of which have been linked to health behaviors (Hampson, Goldberg, Vogt, and Dubanoski (2007), Hampson, Tildesley, Andrews, Luyckx, and Mroczek (2010)), and allow to establishing heterogeneity in peer effects with respect to personality. Third, the Add-Health data interviews high-school students in grades 7-12 (i.e., between age 12 and 18). Since more than $80 \%$ of adult smokers begin smoking before the age of 18 (DHHS (2012)), the age span of the Add-Health data is the most relevant one in terms of smoking prevention efforts.

Our results provide strong evidence that peer effects in smoking are moderated by personality. Individuals who are emotionally unstable face larger peer effects compared to individuals who are emotionally stable. For conscientiousness, we do not find a similar pattern. Although it seems extremely difficult to manipulate the composition of peer groups on the basis of personality, the results do suggest that interventions aimed at groups of emotionally unstable individuals have the largest scope in reducing the uptake of smoking and other unhealthy behaviors in adolescence.

The findings are also suggestive of an important mechanism through which personality affects later life outcomes. We find that emotional stability, which is associated with the skills of self-control and resisting temptation from peers (Costa and McCrae (1992)),

(2007), Boucher, Bramoullé, Djebbari, and Fortin (2014)). The drawback is however that not all classmates are one's peers and, therefore, we prefer to focus on friendship nominations.

${ }^{2}$ This is illustrated perhaps most saliently in the case of peer effects in students' GPA. Here, your friend's GPA appears in the outcome equation for your GPA only because your friend's GPA proxies for unobserved inputs such as motivation and hours of study (Arcidiacono et al. (2012)). 
is important to defy smoking initiation in social interactions among adolescents. Since we find similar patterns for the prevalence of getting drunk, it seems plausible that the skills of resisting temptations and standing up against group pressure are productive more generally in maintaining a healthy lifestyle and perhaps even becoming socioeconomically successful. Our results therefore provide a promising mechanism in the strong association between personality characteristics and later-life outcomes that is so far poorly understood.

This paper is organized as follows. In Section 2, we discuss the literature on peer effects in smoking, and the literature on the relationship between personality and smoking. Section 3 discusses the data, and Section 4 presents the empirical model used to identify peer effects. In Section 5, we discuss our results, after which we present robustness checks in Section 6. Section 7 summarizes and discusses the implications of the results.

\section{Related literature}

In a comprehensive review of the social science literature, Conrad, Flay, and Hill (1992) reported that the most important predictors of smoking initiation are socioeconomic background, social bonding variables, peer effects, and a range of noncognitive skills. In this section, we focus on the latter two, and discuss the literature on peer effects in smoking (Section 2.1) ${ }^{3}$ and the literature on the relationship between personality (noncognitive skills) and smoking (Section 2.2).

\subsection{Peer effects in smoking}

Glaeser and Scheinkman (2003) and Cutler and Glaeser (2010) described various mechanisms that could produce peer effects in smoking. First, peer effects could include what they term "learning," which may have both positive and negative consequences. When your peers smoke, information becomes available about the benefits and costs of smoking and you may act on this. Second, they discuss stigma. When many peers around you smoke, this tends to reduce the negative social stigma that is normally associated with smoking. Third, there may be taste-related interactions, due to a desire for conformity and imitation. In simple terms, it is more pleasurable to do something together. Finally, Cutler and Glaeser (2010) noted that the supply side plays a role, for example, healthy alternatives to cigarettes (e.g., fruit) may be less available in certain neighborhoods.

The empirical identification of peer effects is challenging. First, one should distinguish social effects from correlated effects (selection). Someone's peer group tends to be a group of individuals with similar characteristics and preferences, and so the correlation in outcomes such as smoking could simply be driven by similar preferences. Second, one should distinguish between endogenous social effects and exogenous social effects, commonly known as the reflection problem. Given a dependence of

\footnotetext{
${ }^{3}$ See Sacerdote (2011) for a review on the literature of peer effects in education, and Cawley and Ruhm (2011) for a review of the literature on peer effects in wider health behaviors.
} 
the peers' outcome on the peers' characteristics, it is hard to distinguish between the two.

In the past two decades, many scholars in economics have attempted to estimate the endogenous peer effect in smoking. ${ }^{4}$ In most of the early attempts (Gaviria and Raphael (2001), Powell, Tauras, and Ross (2005), Lundborg (2006), Clark and Lohéac (2007), Kooreman (2007)), the reflection problem is tackled by assuming contextual effects are absent. ${ }^{5}$ In this case, (a subset of) peers' characteristics can serve as instrumental variables (IVs) for the endogenous peer outcome. Moreover, these studies typically used the whole classroom (or school) as the relevant peer group, such that correlated effects are minimized when class (school) fixed effects are taken into account. Most of these studies estimate relatively large endogenous peer effects in smoking.

The next generation of studies has used specific IVs to identify the endogenous peer effects, while allowing for the influence of contextual effects. An early attempt was Norton, Lindrooth, and Ennett (1998), who used neighborhood characteristics as IVs for the endogenous peer effects. Later examples include Eisenberg (2004), who used a friend moving away or graduating as a shock to one's peer group, Fletcher (2010), who used the proportion of classmates of which a household member smokes as instrument for the group average smoking, Cutler and Glaeser (2010), who exploited workplace smoking bans as exogenous shocks in peer's (spousal) smoking behavior, and Argys and Rees (2008), who exploited birth and kindergarten start dates as exogenous variation in the age of one's peers, and find that females with older peers are more likely to smokeconsistent with endogenous peer effects.

In recent years, scholars have either used random assignment of college roommates (Eisenberg, Golberstein, and Whitlock (2014)), or a more structural approach that combined functional form assumptions with exclusion restrictions (Soetevent and Kooreman (2007), Krauth (2007), Card and Giuliano (2013)) to identify peer effects in smoking. With these increasingly convincing identification strategies, the resulting endogenous peer effects become gradually smaller, yet generally survive even in the most convincing designs. Hence, whereas there is disagreement on the most appropriate methodology to establish peer effects, our reading of the literature is that peer effects in smoking seem well established irrespective of the used methodology.

Although the effect on the average individual seems well established, the literature has hardly investigated heterogeneity in peer effects. Given that it is difficult to prevent adolescents from affiliating with peers that may exert negative influences, knowledge on mechanisms and which individuals are particularly susceptible to peer influences in smoking are critical for prevention efforts (Brechwald and Prinstein (2011)). Since peer influence is contingent on openness to influence/susceptibility (Brown, Bakken, Ameringer, and Mahon (2008)), it seems particularly relevant to investigate the moderating role of personality.

\footnotetext{
${ }^{4}$ See Christakis and Fowler (2008) for evidence from the epidemiological literature, and Cohen-Cole and Fletcher (2008a, 2008b), Fowler and Christakis (2008), Lyons (2011), VanderWeele, Ogburn, and Tchetgen Tchetgen (2012) for methodological discussions of these findings.

${ }^{5}$ Kawaguchi (2004) used the individual's perception of peer behavior to overcome the reflection problem.
} 


\subsection{Personality and smoking}

The most widely accepted taxonomy of personality (also known as noncognitive skills) is the so-called "Big Five" (acronym OCEAN, Digman (1990), Matthews, Deary, and Whiteman (2003)). The five factors can be described as:

1. Openness to experience ("the degree to which a person needs intellectual stimulation, change, and variety").

2. Conscientiousness ("the degree to which a person is willing to comply with conventional rules, norms, and standards").

3. Extraversion ("the degree to which a person needs attention and social interaction").

4. Agreeableness ("the degree to which a person needs pleasant and harmonious relations with others").

5. Emotional stability (or neuroticism, "the degree to which an individual experiences the world as threatening and beyond his/her control").

Even though the association between personality and economic outcomes, including health, has been studied extensively in other disciplines (see, e.g., Deary, Weiss, and Batty (2010), for an overview of the psychological literature), in economics personality was for a long time understudied. Interest dates back at least to Bowles and Gintis (1976), but only recently became very popular mainly due to the work by James Heckman and coauthors (Heckman (2000), Heckman, Stixrud, and Urzua (2006)). In particular, Heckman, Stixrud, and Urzua (2006) suggested that personality is at least equally important as cognitive ability in determining adult's outcomes including health behaviors, and Heckman, Pinto, and Savelyev (2013) suggested that influential preschool programs were mainly effective in improving individual's earnings, health, and other socioeconomic outcomes by boosting personality traits.

There are only few studies in economics specifically studying personality traits and health behaviors. Fletcher, Deb, and Sindelar (2009) used Add Health data to show that individuals with low self-control (mainly related to conscientiousness and emotional stability) are less responsive to cigarette taxes, consistent with behavioral economic models of cue-triggered addiction and self-control (Bernheim, Douglas, and Rangel (2004), Gul and Pesendorfer (2004)). Chiteji (2010) used the US Panel Study of Income Dynamics (PSID) and found that future orientation and self-efficacy (related to emotional stability) are associated with better health behavior. Cobb-Clark, Kassenboehmer, and Schurer (2014) used the Australian HILDA data and found that an internal locus of control (also related to emotional stability, whether you think life's outcomes are under our control) is related to better health behavior including reduced smoking. Mendolia and Walker (2014) used the Longitudinal Study of Young People in England and found that individuals with external locus of control, low self-esteem, and low levels of work ethics, are more likely to engage in risky health behaviors including smoking.

These studies suggest that there is an association between certain personality traits and risky health behaviors including smoking. Indeed, in comprehensive reviews of the 
psychology and economics literature, Borghans et al. (2008) and Almlund et al. (2011) concluded that especially conscientiousness and, to a slightly lesser extent, emotional stability are most important in determining later life economic and social outcomes, including health and smoking.

Despite a growing number of studies on personality and health behavior, the mechanisms are unexplored (Almlund et al. (2011)). It is not known how personality affects health behavior and health outcomes. We hypothesize that the susceptibility to peer influences is one of the mechanisms through which personality affects health behaviors. Since the effect of peer influence is known to be moderated by the "openness to influence," but also by the "salience of influencers" (Brown et al. (2008)), it seems plausible that the personalities of both the individual and his/her peers play a role. Therefore, we will investigate heterogeneity in peer effects stratified by the personality of the individual and his/her peers, to test the hypothesis that personality is a key moderator of peer influence in smoking.

\section{Data And Descriptive statistics}

Our study is based on the Add Health survey, ${ }^{6}$ which is a longitudinal study on a nationally representative sample covering adolescents in grade 7 through 12 (average age from 12 to 17) from 132 schools. With the purpose of understanding how social environments and behaviors in adolescence are linked to health and achievement outcomes in young adulthood, the Add Health data contains detailed information about respondents' demographic backgrounds, academic performance, health related behaviors, psychological, and physical well-being. Most uniquely, the Add Health asked each respondent to nominate their male and female friends so that researchers can use the information to construct students' friendship networks.

Four waves of surveys were conducted from 1994 to 2008. In Wave I, a total of approximately 90,000 students were sampled and surveyed at school, and a subset of 20,745 students participated in the in-home survey. The in-home survey data contains more detailed questions on family background than the in-school survey data, and includes information on individual's personality characteristics. In the following waves, all surveys are conducted at home, tracking subsets of the total sample. We only use the Wave I inhome data for its advantage on data coverage. We focus on small- and mid-size schools that have less than 300 students interviewed in the in-home survey, ${ }^{7}$ and we remove ob-

\footnotetext{
${ }^{6}$ This is a program project designed by J. Richard Udry, Peter S. Bearman, and Kathleen Mullan Harris, and funded by a grant P01-HD31921 from the National Institute of Child Health and Human Development, with cooperative funding from 17 other agencies. Special acknowledgment is due to Ronald R. Rindfuss and Barbara Entwisle for assistance in the original design. Persons interested in obtaining data files from Add Health should contact: Add Health, Carolina Population Center, 123 W. Franklin Street, Chapel Hill, NC 27516-2524 (addhealth@unc.edu). No direct support was received from grant P01-HD31921 for this analysis.

${ }^{7}$ We do this for a computational reason since the computation time required increases exponentially with network size. Note that these schools in practice will have a larger number of students, but less than 300 students are interviewed at home.
} 
servations with missing values on basic demographic information. Eventually, we obtain a final sample of 9748 students in 118 schools for our analysis.

We construct the main dependent variable of the paper, smoking, in two different ways. The "Smoking Dummy" variable equals one if a student reported he/she smoked at least once a month during each of the past 12 months, and zero otherwise. The second dependent variable "Smoking Frequency" is defined as the average number of days per week one is smoking.

The Add Health survey allows constructing three out of the big five personality characteristics during adolescence: emotional stability, conscientiousness, and extraversion. ${ }^{8}$ We follow Young and Beaujean (2011) to measure the three personality dimensions by selecting 13 items from the survey according to the Lexical approach and exploratory factor analysis. The details of these 13 items are in the supplementary Appendix Table A.1, available in a supplementary file on the journal website, http: //qeconomics.org/supp/615/supplement.pdf. We identify one main factor for each personality measure, which explains more than $90 \%$ of variation in the corresponding items. The predicted factor scores have a zero mean, and the sign and the magnitude reflect individuals' personalities.

Borghans et al. (2008) suggest that particularly emotional stability and conscientiousness are important in determining smoking. For this reason, we will explore heterogeneity in peer effects along those two dimensions. We do allow extraversion to influence smoking decisions and the nomination of friends, but we will not investigate heterogeneity in the peer effect with respect to extraversion. This is because we found evidence that extraversion is potentially affected by peers (see Section 6.1), such that the subgroups defined by extraversion are endogenously determined and subject to change depending on the composition of the peer group.

In the model specification, we additionally include a wide array of demographic and socioeconomic characteristics that determine the individual's smoking decision ("own effects"), and also the smoking decisions of his/her friends ("contextual effects"). Most variables are relatively standard and are listed in Table 1 with summary statistics. The variables low parent control (e.g., "do your parents let you make your own decisions?") and maternal care (e.g., "How much do you think your mother cares about you?") are constructed from the Add Health Wave I in-home survey following Driscoll, Russell, and Crockett (2008) and Shakya, Christakis, and Fowler (2012) by taking average responses from seven and four survey questions, respectively.

Based on the whole sample, $22.4 \%$ of students are identified as smokers. There are slightly more girls $(53.4 \%)$ than boys $(46.6 \%)$ in our sample. In terms of race, White $(54 \%)$ is the majority in the sample, followed by Black (22.8\%) and Asian (11\%). 94\% of students report that they have received information on the health consequence of smoking (school taught) in class. There are $64.3 \%$ of students having at least one parent previously or currently smoking (smoke parent) at home. The average of low parent control

\footnotetext{
${ }^{8}$ The timing of the personality measures is very similar to other surveys like the British Cohort Study (age 10, see Conti, Heckman, and Urzua (2010)), National Child Development Study (ages 7, 11, and 16, see Conti and Hansman (2013)), National Longitudinal Study of Youth 79 (ages 14 to 21, see Heckman, Stixrud, and Urzua (2006)), Longitudinal Study of Young People in England (age 14, see Mendolia and Walker (2014)), and the Terman data (age 12, see Savelyev (2014)).
} 
TABLE 1. Summary statistics for the whole sample and by personality measures.

\begin{tabular}{|c|c|c|c|c|c|c|c|c|c|c|c|c|}
\hline & \multicolumn{4}{|c|}{ Whole Sample } & \multicolumn{4}{|c|}{ Emotional Stability } & \multicolumn{4}{|c|}{ Conscientiousness } \\
\hline & \multirow[b]{2}{*}{ Mean } & \multirow[b]{2}{*}{ S.D. } & \multirow[b]{2}{*}{ Min } & \multirow[b]{2}{*}{ Max } & \multicolumn{2}{|c|}{ Above Average } & \multicolumn{2}{|c|}{ Below Average } & \multicolumn{2}{|c|}{ Above Average } & \multicolumn{2}{|c|}{ Below Average } \\
\hline & & & & & Mean & S.D. & Mean & S.D. & Mean & S.D. & Mean & S.D. \\
\hline Smoke dummy & 0.224 & 0.417 & 0.000 & 1.000 & 0.184 & 0.388 & 0.261 & 0.439 & 0.205 & 0.404 & 0.247 & 0.431 \\
\hline Smoke frequency & 0.904 & 2.162 & 0.000 & 7.000 & 0.721 & 1.955 & 1.070 & 2.321 & 0.832 & 2.095 & 0.989 & 2.236 \\
\hline Drunk & 0.311 & 0.463 & 0.000 & 1.000 & 0.272 & 0.445 & 0.346 & 0.476 & 0.296 & 0.457 & 0.327 & 0.469 \\
\hline Emotional stability & 0.015 & 0.715 & -4.033 & 1.021 & 0.636 & 0.285 & -0.547 & 0.485 & 0.146 & 0.670 & -0.140 & 0.735 \\
\hline Conscientiousness & -0.032 & 0.831 & -3.790 & 1.565 & 0.188 & 0.877 & -0.232 & 0.733 & 0.536 & 0.499 & -0.701 & 0.619 \\
\hline Extraversion & 0.009 & 0.840 & -2.385 & 1.260 & 0.193 & 0.806 & -0.157 & 0.835 & 0.082 & 0.838 & -0.077 & 0.833 \\
\hline Male & 0.466 & 0.499 & 0.000 & 1.000 & 0.517 & 0.500 & 0.420 & 0.494 & 0.475 & 0.499 & 0.456 & 0.498 \\
\hline White & 0.541 & 0.498 & 0.000 & 1.000 & 0.538 & 0.499 & 0.544 & 0.498 & 0.530 & 0.499 & 0.554 & 0.497 \\
\hline Black & 0.228 & 0.419 & 0.000 & 1.000 & 0.258 & 0.438 & 0.200 & 0.400 & 0.239 & 0.427 & 0.215 & 0.411 \\
\hline Asian & 0.110 & 0.313 & 0.000 & 1.000 & 0.100 & 0.301 & 0.119 & 0.324 & 0.107 & 0.309 & 0.115 & 0.319 \\
\hline Hisp & 0.064 & 0.244 & 0.000 & 1.000 & 0.048 & 0.214 & 0.078 & 0.267 & 0.068 & 0.253 & 0.058 & 0.233 \\
\hline Other race & 0.057 & 0.232 & 0.000 & 1.000 & 0.055 & 0.229 & 0.059 & 0.235 & 0.056 & 0.230 & 0.059 & 0.235 \\
\hline School taught & 0.934 & 0.248 & 0.000 & 1.000 & 0.942 & 0.233 & 0.927 & 0.261 & 0.940 & 0.238 & 0.928 & 0.259 \\
\hline Smoke parent & 0.643 & 0.479 & 0.000 & 1.000 & 0.632 & 0.482 & 0.652 & 0.476 & 0.634 & 0.482 & 0.654 & 0.476 \\
\hline Prof & 0.275 & 0.447 & 0.000 & 1.000 & 0.299 & 0.458 & 0.253 & 0.435 & 0.278 & 0.448 & 0.272 & 0.445 \\
\hline Home & 0.134 & 0.341 & 0.000 & 1.000 & 0.124 & 0.330 & 0.143 & 0.350 & 0.138 & 0.345 & 0.130 & 0.337 \\
\hline Nonprof & 0.427 & 0.495 & 0.000 & 1.000 & 0.416 & 0.493 & 0.437 & 0.496 & 0.428 & 0.495 & 0.426 & 0.495 \\
\hline Low parent control & 0.741 & 0.217 & 0.000 & 1.000 & 0.738 & 0.217 & 0.744 & 0.217 & 0.741 & 0.219 & 0.742 & 0.215 \\
\hline Maternal care & 4.550 & 0.526 & 1.000 & 5.000 & 4.627 & 0.485 & 4.481 & 0.552 & 4.596 & 0.500 & 4.497 & 0.550 \\
\hline Sample size & \multicolumn{4}{|c|}{9728} & \multicolumn{2}{|c|}{4619} & \multicolumn{2}{|c|}{5109} & \multicolumn{2}{|c|}{5258} & \multicolumn{2}{|c|}{4470} \\
\hline
\end{tabular}

Note: High (low) personality values refer to individuals' personality index which is above (below) the mean. "School taught" means the consequence of smoking is taught in school. "Smoke parent" means either resident father or mother has ever smoked at home. "Prof" means resident mother works as a professional (response 1 to 3 in Add Health survey item H1rm4), "Home" indicates resident mother does not work (response 16 in H1rm4). "Nonprof" indicates resident mother works in other categories (responses 4 to 14 in H1rm4). The omitted group for resident mother's occupation is the response 15 (other jobs) in H1rm4. "Low parent control" reflects the degree to which your parents let you make your own decisions and is constructed by the average of items from H1WP1 to H1WP7. "Maternal care" reflects how much you think your mother cares about you and is constructed by the average of items from h1wp9 to h1wp12. 


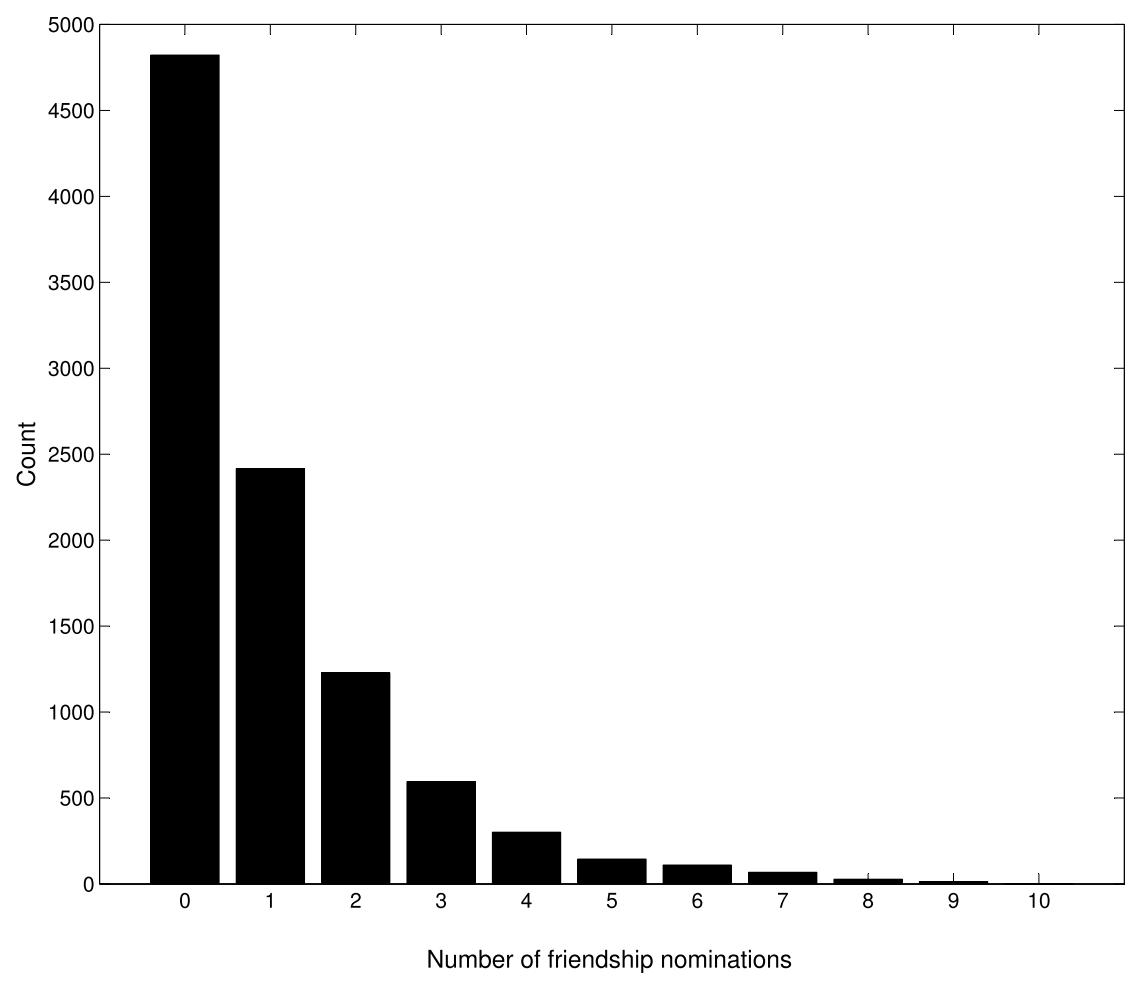

FiguRE 1. Distribution of friendship nominations based on our network samples from the Add Health Wave I in-home survey.

is 0.741 (the value 1 represents weak control and the value 0 represents strong control), and the average of maternal care is 4.55 (the value 5 represents high warmth and the value 1 represents low warmth).

Figure 1 depicts the distribution of the number of friendship nominations that is observed in our sample and Table 2 shows the average number of nominated friends stratified by the personality measures of emotional stability and conscientiousness. The average number of nominated friends is 2.76 in the Add Health in-school sample, whereas the average number of observed friends in the in-home survey is on average slightly more than one. Hence we observe only a subset of the full friendship network among the in-home survey respondents, a phenomenon known as the missing link problem. Reassuringly, in Section 6.2 we show that restricting to the so-called saturated sample or applying the analysis to the in-school sample for which we observe the full friendship network, our main results are not affected. Table 2 further shows that for emotional stability the average number of nominations along the diagonal is slightly larger than off the diagonal. This suggests that there is some homophily in terms of personality (Girard, Hett, and Schunk (2015)), something we will explore in more detail below.

Table 3 explores our main hypothesis in a descriptive way, and reveals three interesting observations: (i) smoking prevalence and smoking frequency are lower among 
TABLE 2. Average number of nominated friends within and across personality groups.

\begin{tabular}{lccccccr}
\hline & \multicolumn{3}{c}{ Emotional Stability } & & \multicolumn{3}{c}{ Conscientiousness } \\
\cline { 2 - 3 } & Low & High & Total & & Low & High & Total \\
\hline Low & 0.5265 & 0.4977 & 1.0242 & & 0.4606 & 0.5405 & 1.0011 \\
High & 0.4997 & 0.5501 & 1.0498 & & 0.4711 & 0.5953 & 1.0664 \\
\hline
\end{tabular}

Note: The above statistics are based on our network samples from the Add Health Wave I in-home survey. "Low" refers to the case where the personality characteristic (emotional stability or conscientiousness) is strictly below the school mean of the factor score, whereas "high" refers to the case where the personality characteristic is at or above the school mean of the factor score.

TABLE 3. Average smoking outcome across personality and peer outcome groups.

\begin{tabular}{lcccccccc}
\hline & \multicolumn{3}{c}{ Smoke Dummy } & & \multicolumn{3}{c}{ Smoke Frequency } \\
\cline { 2 - 3 } & Overall & Friends $>$ Avg & Friends $\leq$ Avg & & Overall & Friends $>$ Avg & Friends $\leq$ Avg \\
\hline Emotionally unstable & 0.261 & 0.416 & 0.227 & & 1.070 & 1.969 & 0.915 \\
Emotionally stable & 0.184 & 0.319 & 0.160 & & 0.721 & 1.296 & 0.639 \\
Low conscientiousness & 0.247 & 0.406 & 0.215 & & 0.989 & 1.885 & 0.843 \\
High conscientiousness & 0.205 & 0.346 & 0.118 & & 0.832 & 1.580 & 0.715 \\
\hline
\end{tabular}

Note: "Friends > Avg" refers to the subgroup of students whose friends smoke more than the overall average. "Friends $\leq$ Avg" refers to the subgroup of students whose friends' smoke less than the overall average.

emotionally stable and conscientious individuals, (ii) when your friends are smoking (frequently), you are more likely to smoke (frequently), and (iii) emotionally unstable and nonconscientious individuals seem more affected by their peers. The latter observation follows since the difference in smoking among individuals with friends more or less likely to smoke (i.e., the difference between columns 2 and 3, and between columns 5 and 6), is larger for emotionally unstable and less conscientious individuals. We now explain our methodology to identify whether these descriptive patterns survive when using a more rigorous approach of identifying peer effects.

\section{Methodology}

\subsection{SAR model}

The traditional workhorse model for studying social interactions is the linear-inmeans model. However, the linear-in-means model suffers from the reflection problem (Manski (1993)), which prevents researchers from distinguishing between endogenous and contextual peer effects. The reflection problem can be solved by utilizing information of detailed friendship links among individuals, summarized by a spatial weight matrix in the Spatial Autoregressive (SAR) model. In the SAR model, both the endogenous and contextual effects are identified as long as individuals' friends 
are not perfectly overlapping (Bramoullé, Djebbari, and Fortin (2009), Lin (2010), Lee, Liu, and Lin (2010)). ${ }^{9}$

Most of the existing SAR model applications (Bramoullé, Djebbari, and Fortin (2009), Lin (2010), Lee, Liu, and Lin (2010), Fortin and Yazbeck (2015), Hsieh and Lee (2016); among others) focus on a homogenous endogenous peer effect, which can be regarded as the average of heterogeneous peer effects. ${ }^{10}$ Even though the average endogenous peer effect in smoking initiation is certainly of interest, our main objective is to study the moderating role of personality. In other words, we intend to investigate whether peer effects are stronger among individuals who are emotionally unstable or less conscientious. Therefore, we extend the conventional SAR model to capture heterogeneous endogenous peer influences from friends with different personalities.

Our model considers an environment where students are placed in schools $g \in$ $\{1, \ldots, G\}$. In school $g$, student $i$ 's smoking behavior is represented by the variable $y_{i, g}$ and his/her personality is represented by a $R$-dimensional row vector $s_{i, g}$. The other individual exogenous characteristics are represented by a $K$-dimensional row vector $x_{i, g}$. The vector $Y_{g}\left(m_{g} \times 1\right)$, matrix $S_{g}\left(m_{g} \times R\right)$, and matrix $X_{g}\left(m_{g} \times K\right)$ summarize smoking variables, personalities, and characteristics of $m_{g}$ students in school $g$, respectively. The friendship network in group $g$ is represented by a $m_{g} \times m_{g}$ spatial weight matrix $W_{g}$. Each element of $W_{g}, w_{i j, g}$, is a binary indicator which equals one if individual $i$ sends a friendship nomination to individual $j$, and zero otherwise. Since friendship nominations are directional without guaranteed reciprocality, $W_{g}$ is not necessarily symmetric.

The heterogeneous network interaction equation for student $i$ 's smoking moderated by the $r$ th personality measure is specified as

$$
\begin{aligned}
y_{i, g}= & \lambda_{11} I\left(s_{i r, g}<\bar{S}_{r, g}\right) \sum_{j \neq i} w_{i j, g} I\left(s_{j r, g}<\bar{S}_{r, g}\right) y_{j, g} \\
& +\lambda_{12} I\left(s_{i r, g}<\bar{S}_{r, g}\right) \sum_{j \neq i} w_{i j, g} I\left(s_{j r, g} \geq \bar{S}_{r, g}\right) y_{j, g} \\
& +\lambda_{21} I\left(s_{i r, g} \geq \bar{S}_{r, g}\right) \sum_{j \neq i} w_{i j, g} I\left(s_{j r, g}<\bar{S}_{r, g}\right) y_{j, g} \\
& +\lambda_{22} I\left(s_{i r, g} \geq \bar{S}_{r, g}\right) \sum_{j \neq i} w_{i j, g} I\left(s_{j r, g} \geq \bar{S}_{r, g}\right) y_{j, g} \\
& +x_{i, g} \beta_{1}+\sum_{j \neq i} w_{i j, g} x_{i, g} \beta_{2}+s_{i, g} \beta_{3}+\sum_{j \neq i} w_{i j, g} s_{j, g} \beta_{4}+\alpha_{g}+\varepsilon_{i, g}
\end{aligned}
$$

\footnotetext{
${ }^{9}$ The SAR model imposes a linear relationship, which ensures a unique equilibrium if the social interaction parameter is well-defined and nonnegative (Moffitt (2001), Ballester, Calvó-Armengol, and Zenou (2006)). The estimation of linear models can be motivated using a theoretical framework where each individual maximizes a quadratic utility function depending on his outcome and on his reference group's mean expected outcome and mean characteristics (Bramoullé, Djebbari, and Fortin (2009)). Implicitly, it is assumed that social interactions have reached the single noncooperative (Nash) equilibrium.

${ }^{10}$ Some recent exceptions include Card and Giuliano (2013), who study heterogeneity with respect to gender, and Lin and Weinberg (2014), who study heterogeneity with respect to reciprocated and unreciprocated friends.
} 
for $i=1, \ldots, m_{g}$, where $I(A)$ denotes an indicator function which equals one if $A$ is satisfied and equals zero, otherwise. $\bar{S}_{r, g}$ denotes the average of the $r$ th personality measure in group $g$.

The innovation of equation (1) compared to the conventional SAR model is to allow for differential peer effects according to individuals' own and friends' personalities. To be specific, consider the case of emotional stability: The coefficient $\lambda_{11}$ captures the endogenous peer effect for a pair of individuals that are both emotionally unstable. Coefficients $\lambda_{12}$ and $\lambda_{21}$ capture endogenous peer effects for the cases that one individual is emotionally stable, but the other one is emotionally unstable. The coefficient $\lambda_{22}$ considers the case that both individuals are emotionally stable. The dichotomization of personality into two types (emotionally unstable or emotionally stable) is defined by whether the individual's emotional stability score is below or above the school average.

The coefficients $\beta_{1}$ and $\beta_{3}$ capture the individual ("own") effect of exogenous characteristics $x$ and personalities $s$, respectively. The coefficients $\beta_{2}$ and $\beta_{4}$ reflect the contextual effects from exogenous characteristics and personalities, respectively. ${ }^{11}$ The term $\alpha_{g}$ represents the group fixed effect, which plays a key role in capturing the environmental correlated effects shared by all members in the same group, for example, teacher quality, school facilities, etc. The error term $\varepsilon_{i, g}$ is assumed normally distributed with a zero mean and a variance equal to $\sigma_{\varepsilon}^{2}$.

For the ease of presentation, the vector expression of equation (1) is

$$
\begin{aligned}
Y_{g}= & \lambda_{11} W_{11, g} Y_{g}+\cdots+\lambda_{22} W_{22, g} Y_{g}+X_{g} \beta_{1}+W_{g} X_{g} \beta_{2}+S_{g} \beta_{3} \\
& +W_{g} S_{g} \beta_{4}+\ell_{g} \alpha_{g}+\varepsilon_{g},
\end{aligned}
$$

for $g=1, \ldots, G$. The spatial weight matrix $W_{g}$ is now divided into $2 \times 2$ blocks, where each block, $W_{g}^{p q}, p, q=1,2$, represents the subnetwork between individuals in the personality subgroups 1 and $2 .{ }^{12} W_{p q, g}$ is a $m_{g} \times m_{g}$ matrix with the corresponding $(p, q)$ th block equal to $W_{g}^{p q}$ and 0 elsewhere, $X_{g}$ and $S_{g}$ are matrices of individuals characteristics and personalities, respectively, and $\ell_{g}$ is a $m_{g} \times 1$ vector of ones.

One choice regarding the SAR model specification is whether to use the raw spatial weight matrix or to row-normalize it. In the raw case, every friend receives a weight of one, whereas the row-normalized case ensures that the sum of each row of the spatial weight matrix equals one. For example, if an individual nominates four

\footnotetext{
${ }^{11}$ Although it is straightforward to generalize equation (1) with heterogeneous contextual effects, in order to focus on the endogenous effect as well as maintain model parsimony, we leave contextual effects to be homogenous in this paper.

${ }^{12}$ In each group, we reorder individuals based on their personality measures from low to high values. All variables, including $Y_{g}, X_{g}$, and the spatial weight matrix $W_{g}$, are rearranged accordingly. To divide individuals into personality types, we use the average personality measure as the threshold. Let us say it divides $m_{g}$ individuals in group $g$ into two subgroups, with $m_{1 g}$ and $m_{g}-m_{1 g}$ individuals, respectively. Individuals indexed from one to $m_{1 g}$ score lowest on the personality trait and individuals indexed from $m_{1 g}+1$ to $m_{g}$ score highest on the personality trait. The subnetwork $W_{g}^{11}$ refers to the $\left(m_{1 g} \times m_{1 g}\right)$ matrix that summarizes connections between the first $m_{1 g}$ individuals. The subnetwork $W_{g}^{12}$ refers to the $\left(m_{1 g} \times\left(m_{g}-m_{1 g}\right)\right)$ matrix between the first $m_{1 g}$ and the other $m_{g}-m_{1 g}$ individuals. The other two matrices $W_{g}^{21}$ and $W_{g}^{22}$ are constructed in the same way.
} 
friends, they all receive a weight of one-fourth. Liu, Patacchini, and Zenou (2014) interpret the SAR model as the "local average" model if the matrix is row-normalized, with network participants obtaining higher marginal utilities by conforming to the social norm of their reference groups. When the raw matrix is used the SAR model is interpreted as the "local aggregate" model where network participants obtain higher marginal utilities from having more friends. In our main results, we choose to use the raw weight matrix, but we investigate robustness to using the row-normalized matrix in Section 6.2.

\subsection{SC-SAR model with unobserved individual heterogeneity}

SC-SAR model The SAR model is fully capable of solving the reflection problem. However, the issue of correlated effects cannot be adequately solved by the conventional SAR model. One can include network fixed effects to account for common environments among individuals within the network, but one cannot rule out that there are individual correlated effects. Unobserved individual characteristics that are correlated to smoking may also affect the selection of friends. For example, an individual's unobserved attitude toward freshness and excitement may not only affect the smoking decision, but also the friendship choices. As a result, the peers' outcome will-indirectly through the selection of friends-be influenced by the same characteristics that influence your own outcome. In terms of equation (2), the matrices $W_{p q, g}, p, q=1,2$, and the outcome vector $Y_{g}$ are both influenced by some unobserved individual traits, so $W_{p q, g}, p, q=1,2$, is endogenous, and the estimates of the endogenous peer effects will be biased.

To overcome this issue, Hsieh and Lee (2016) introduced the selection correctedSAR (SC-SAR) model. Effectively, the SC-SAR model introduces an additional equation in which the spatial weight matrix $W_{g}$ is endogenously determined, and allows observed and unobserved (latent) characteristics to influence both the friendship link formation and the individual's outcome. ${ }^{13}$ The latent variables are denoted by $z_{i, g}$ and are assumed to be multidimensional (with a total of $\bar{d}$ dimensions) to accommodate the unknown number of underlying individual correlated effects. The outcome equation of the SCSAR model can be written down as

$$
\begin{aligned}
Y_{g}= & \lambda_{11} W_{11, g} Y_{g}+\cdots+\lambda_{22} W_{22, g} Y_{g}+X_{g} \beta_{1}+W_{g} X_{g} \beta_{2} \\
& +S_{g} \beta_{3}+W_{g} S_{g} \beta_{4}+Z_{g} \delta_{1}+\ell_{g} \alpha_{g}+u_{g},
\end{aligned}
$$

where $u_{g}$ is the error term, and $Z_{g}=\left(z_{1, g}^{\prime}, \ldots, z_{m_{g}, g}^{\prime}\right)^{\prime}$. Essentially, compared to the SAR model of equation (2), the extra term $Z_{g} \delta_{1}$ in equation (3) represents a control function to handle the endogeneity of $W_{g}$ (Navarro (2008)).

\footnotetext{
${ }^{13} \mathrm{An}$ alternative approach to take into account the endogeneity of friendship formation is provided by Badev (2017). He proposes a strategic game model in which smoking decisions (the outcome) may affect friendship formation and vice versa.
} 
The link formation equation of the SC-SAR model endogenously models the individual elements $w_{i j, g}$ of the spatial weight matrix $W_{g}$, and is specified as

$$
\begin{aligned}
P\left(w_{i j, g} \mid c_{i j, g}, s_{i g}, s_{j, g}, z_{i, g}, z_{j, g}\right)= & \left(\frac{\exp \left(\psi_{i j, g}\right)}{1+\exp \left(\psi_{i j, g}\right)}\right)^{w_{i j, g}}\left(\frac{1}{1+\exp \left(\psi_{i j, g}\right)}\right)^{1-w_{i j, g}}, \\
\psi_{i j, g}= & c_{i j, g} \gamma_{0}+\gamma_{1}\left|s_{i 1, g}-s_{j 1, g}\right|+\cdots+\gamma_{R}\left|s_{i R, g}-s_{j R, g}\right| \\
& +\eta_{1}\left|z_{i 1, g}-z_{j 1, g}\right|+\cdots+\eta_{\bar{d}}\left|z_{i \bar{d}, g}-z_{j \bar{d}, g}\right| .
\end{aligned}
$$

Hence, the probability to form a link between individual $i$ and individual $j$ in group $g$, $P\left(w_{i j, g}\right)$ in equation (4) is estimated through a logit model determined by a latent index $\psi_{i j, g}$. This latent index in turn is determined by the difference in characteristics between individuals $i$ and $j$, where the more dissimilar individuals are, the less likely they are to become friends. We include differences in personality between individuals to capture the homophily effect from personalities. In the same spirit, the difference in the latent variables $z$ reflects homophily in terms of unobserved characteristics between individuals $i$ and $j . c_{i j, g}$ represents the $\bar{q}$-dimensional dyad-specific variables between individuals $i$ and $j$, for example, whether individual $i$ and $j$ are of the same gender, age, and race.

For identification of the parameters, we have to impose the assumptions that (1) the variance of $z_{i, g}$ is normalized to one, (2) different dimensions of $z_{i, g}$ are independent of each other, (3) $z_{i, g}$ follows a known distribution, in our case a Normal distribution, and (4) the magnitude of the homophily coefficients of $z_{i, g}$ in equation (4) follows a descending order, that is, $\left|\eta_{1}\right| \geq\left|\eta_{2}\right| \geq \cdots \geq\left|\eta_{\bar{d}}\right|$ (see the supplementary Appendix B for more detail). Even though these assumptions, combined with the functional form assumptions in equations (3) and (4), are sufficient for identification, an additional source of identification comes from the dyad-specific variables $c_{i j, g}$ and $\left|s_{i r, g}-s_{j r, g}\right|$ 's. These variables are defined at the dyad level (i.e., they are potentially different for every combination of friends $i$ and $j$ ) and, therefore, form a natural exclusion restriction from the outcome equation, which is defined at the individual level. Apart from the difference in dimension, in Section 6.4 below we present additional evidence on the validity of this exclusion restriction.

Naturally, for an unbiased estimate of the endogenous peer effect, we have to assume that conditional on the observed and unobserved latent individual characteristics, and the group fixed effect, the spatial weight matrix $W_{g}$ is uncorrelated with the error term $u_{g}$ in equation (3).

Unobserved contextual effects Whereas the SC-SAR model introduced by Hsieh and Lee (2016) goes a long way in dealing with the endogeneity of the spatial weight matrix $W_{g}$, it still does not fully account for the potential endogeneity of the peer's outcome. As argued by Fruehwirth (2014), the peer outcome is likely to reflect unobserved contextual effects and this will contaminate the true endogenous peer effects. In simple terms, if the friend's smoking decision is determined partly by, say, intelligence, and we do not control for the contextual effect of friend's intelligence, then this will be absorbed into the endogenous peer effect of smoking. 
To estimate a clean version of the endogenous peer effects, we add contextual latent variables $W_{g} Z_{g}$ to the outcome equation to account for possibly omitted contextual effects. Thus, the extended outcome equation is written as ${ }^{14}$

$$
\begin{aligned}
Y_{g}= & \lambda_{11} W_{11, g} Y_{g}+\cdots+\lambda_{22} W_{22, g} Y_{g}+X_{g} \beta_{1}+W_{g} X_{g} \beta_{2}+S_{g} \beta_{3}+W_{g} S_{g} \beta_{4} \\
& +Z_{g} \delta_{1}+W_{g} Z_{g} \delta_{2}+\ell_{g} \alpha_{g}+u_{g},
\end{aligned}
$$

where $u_{g} \sim$ i.i.d. $\mathcal{N}_{m_{g}}\left(0, \sigma_{u}^{2} I_{m_{g}}\right)$.

The extended outcome model of equation (5), combined with the link formation model of equation (4) forms our extended SC-SAR model. This model accounts for (i) the reflection problem through the use of nonoverlapping friendship nominations in the SAR model, (ii) network-level correlated effects through the use of network fixed effects, (iii) the endogeneity of the spatial weight matrix through the use of dyad-specific variables as exclusion restrictions and latent variables in both equations of the SC-SAR model, and (iv) unobserved contextual effects through our extension of the SC-SAR model.

We follow Hsieh and Lee (2016) to use a Bayesian approach to estimate this extended SC-SAR model, which is effective in handling estimation of models with latent variables (Zeger and Rezaul Karim (1991)). A full discussion of the estimation of the SC-SAR model can be found in the supplementary Appendix C.

\section{Results}

\subsection{The peer effects on smoking: SAR model}

We first present the baseline estimate for the peer effect on smoking from the SAR model in Table 4. When a homogenous peer effect is considered, the estimated endogenous effect for the binary indicator of smoking equals 0.0922 , which implies that when one of individual's friends changes from a nonsmoker to a smoker, the individual increases his/her chance of being a smoker by 9.22 percentage points. The equivalent estimate for smoking frequency is 0.0947 , which implies that when a friend smokes one day per week extra, the individual will smoke 0.09 days per week extra. The total peer effect is roughly the same when we multiply this estimate with the number of peers, since the average number of peers is one in this sample (Table 2). These estimates of the SAR model are subject to potential bias due to individual correlated effects, but they are very close to the result obtained in Card and Giuliano (2013), and to the range reported in the literature varying from around 0.05 (Clark and Lohéac (2007), Fletcher (2010)) to around 0.15 (Gaviria and Raphael (2001), Powell, Tauras, and Ross (2005), Lundborg (2006), Krauth (2007)).

\footnotetext{
${ }^{14}$ Methodologically, this is a straightforward extension, yet empirically it turns out to be very important. In the supplementary Appendix Table A.2, we present estimates of the SC-SAR model without latent contextual effects. Compared with our main results in Table 5, for the binary indicator of smoking, the endogenous peer effect is estimated to be 0.0676 without, and 0.0374 with latent contextual effects. This is a difference of $80 \%$, and shows that leaving out unobserved contextual effects overestimates the endogenous peer effect considerably.
} 
TABLE 4. Peer effects on smoking dummy and frequency—SAR models with both networks and personalities assumed exogenous.

\begin{tabular}{|c|c|c|c|c|c|c|c|c|}
\hline \multirow{2}{*}{ Endogenous effect } & \multicolumn{4}{|c|}{ Smoke Dummy } & \multicolumn{4}{|c|}{ Smoke Frequency } \\
\hline & \multicolumn{2}{|c|}{ Homogeneous } & ES & $\mathrm{CO}$ & \multicolumn{2}{|c|}{ Homogeneous } & ES & $\mathrm{CO}$ \\
\hline & $\begin{array}{l}0.0922^{* * *} \\
(0.0074)\end{array}$ & $\begin{array}{l}0.0842^{* * *} \\
(0.0077)\end{array}$ & & & $\begin{array}{l}0.0947^{* * *} \\
(0.0040)\end{array}$ & $\begin{array}{l}0.0911^{* * *} \\
(0.0057)\end{array}$ & & \\
\hline Low-to-low $\left(\lambda_{11}\right)$ & & & $\begin{array}{l}0.1119^{* * *} \\
(0.0127)\end{array}$ & $\begin{array}{l}0.0914^{* * *} \\
(0.0156)\end{array}$ & & & $\begin{array}{l}0.1243^{* * *} \\
(0.0129)\end{array}$ & $\begin{array}{l}0.0965^{* * *} \\
(0.0164)\end{array}$ \\
\hline High-to-low $\left(\lambda_{12}\right)$ & & & $\begin{array}{l}0.0614^{* * *} \\
(0.0188)\end{array}$ & $\begin{array}{l}0.0866^{* * *} \\
(0.0175)\end{array}$ & & & $\begin{array}{l}0.1257^{* * *} \\
(0.0224)\end{array}$ & $\begin{array}{l}0.1025^{* * *} \\
(0.0205)\end{array}$ \\
\hline Low-to-high $\left(\lambda_{21}\right)$ & & & $\begin{array}{l}0.0802^{* * *} \\
(0.0175)\end{array}$ & $\begin{array}{l}0.0807^{* * *} \\
(0.0176)\end{array}$ & & & $\begin{array}{l}0.0475^{* * *} \\
(0.0194)\end{array}$ & $\begin{array}{l}0.0948^{* * *} \\
(0.0209)\end{array}$ \\
\hline High-to-high $\left(\lambda_{22}\right)$ & & & $\begin{array}{l}0.0700^{* * *} \\
(0.0171)\end{array}$ & $\begin{array}{l}0.0802^{* * *} \\
(0.0137)\end{array}$ & & & $\begin{array}{l}0.0610^{* * *} \\
(0.0188)\end{array}$ & $\begin{array}{l}0.0907^{* * *} \\
(0.0137)\end{array}$ \\
\hline \multicolumn{9}{|l|}{ Own effect } \\
\hline Emotional stability & & $\begin{array}{c}-0.0268^{* * *} \\
(0.0064)\end{array}$ & $\begin{array}{c}-0.0256^{\text {*** }} \\
(0.0066)\end{array}$ & $\begin{array}{c}-0.0276^{\text {*** }} \\
(0.0063)\end{array}$ & & $\begin{array}{c}-0.0946^{* * *} \\
(0.0327)\end{array}$ & $\begin{array}{c}-0.0580 \\
(0.0341)\end{array}$ & $\begin{array}{c}-0.0945^{* * *} \\
(0.0327)\end{array}$ \\
\hline Conscientiousness & & $\begin{array}{c}-0.0170^{\text {*** }} \\
(0.0051)\end{array}$ & $\begin{array}{c}-0.0170^{\text {*** }} \\
(0.0051)\end{array}$ & $\begin{array}{c}-0.0161^{\text {*** }} \\
(0.0053)\end{array}$ & & $\begin{array}{r}-0.0477^{*} \\
(0.0267)\end{array}$ & $\begin{array}{r}-0.0473^{*} \\
(0.0267)\end{array}$ & $\begin{array}{r}-0.0451^{*} \\
(0.0275)\end{array}$ \\
\hline Extraversion & & $\begin{array}{c}-0.0476^{* * *} \\
(0.0051)\end{array}$ & $\begin{array}{c}-0.0477^{* * *} \\
(0.0051)\end{array}$ & $\begin{array}{c}-0.0475^{* * *} \\
(0.0051)\end{array}$ & & $\begin{array}{c}-0.2775^{* * *} \\
(0.0271)\end{array}$ & $\begin{array}{c}-0.2792^{* * *} \\
(0.0267)\end{array}$ & $\begin{array}{c}-0.2776^{* * *} \\
(0.0268)\end{array}$ \\
\hline Parent smoke & $\begin{array}{l}0.0760^{* * *} \\
(0.0087)\end{array}$ & $\begin{array}{l}0.0721^{* * *} \\
(0.0086)\end{array}$ & $\begin{array}{l}0.0727^{* * *} \\
(0.0085)\end{array}$ & $\begin{array}{l}0.0724^{* * *} \\
(0.0085)\end{array}$ & $\begin{array}{l}0.3751^{* * *} \\
(0.0443)\end{array}$ & $\begin{array}{l}0.3564^{* * *} \\
(0.0455)\end{array}$ & $\begin{array}{l}0.3614^{* * *} \\
(0.0447)\end{array}$ & $\begin{array}{l}0.3563^{* * *} \\
(0.0443)\end{array}$ \\
\hline Low parent control & $\begin{array}{l}0.1127^{* * *} \\
(0.0198)\end{array}$ & $\begin{array}{l}0.1142^{* * *} \\
(0.0197)\end{array}$ & $\begin{array}{l}0.1164^{* * *} \\
(0.0194)\end{array}$ & $\begin{array}{l}0.1157^{* * *} \\
(0.0195)\end{array}$ & $\begin{array}{l}0.4875^{* * *} \\
(0.1040)\end{array}$ & $\begin{array}{l}0.4862^{* * *} \\
(0.1015)\end{array}$ & $\begin{array}{l}0.4808^{* * *} \\
(0.1026)\end{array}$ & $\begin{array}{l}0.4838^{* * *} \\
(0.1011)\end{array}$ \\
\hline Maternal care & $\begin{array}{c}-0.0555^{* * *} \\
(0.0077)\end{array}$ & $\begin{array}{c}-0.0366^{* * *} \\
(0.0079)\end{array}$ & $\begin{array}{c}-0.0349^{* * *} \\
(0.0076)\end{array}$ & $\begin{array}{c}-0.0348^{* * *} \\
(0.0077)\end{array}$ & $\begin{array}{c}-0.2867^{* * *} \\
(0.0400)\end{array}$ & $\begin{array}{c}-0.2015^{* * *} \\
(0.0406)\end{array}$ & $\begin{array}{c}-0.2049^{* * * *} \\
(0.0430)\end{array}$ & $\begin{array}{c}-0.1978^{* * *} \\
(0.0408)\end{array}$ \\
\hline School taught & $\begin{array}{c}-0.0118 \\
(0.0167)\end{array}$ & $\begin{array}{c}-0.0039 \\
(0.0166)\end{array}$ & $\begin{array}{c}-0.0023 \\
(0.0165)\end{array}$ & $\begin{array}{c}-0.0026 \\
(0.0166)\end{array}$ & $\begin{array}{c}-0.0773 \\
(0.0875)\end{array}$ & $\begin{array}{c}-0.0452 \\
(0.0878)\end{array}$ & $\begin{array}{c}-0.0479 \\
(0.0872)\end{array}$ & $\begin{array}{r}-0.0446 \\
(0.0863)\end{array}$ \\
\hline Male & $\begin{array}{c}-0.0031 \\
(0.0083)\end{array}$ & $\begin{array}{c}0.0067 \\
(0.0083)\end{array}$ & $\begin{array}{c}0.0068 \\
(0.0083)\end{array}$ & $\begin{array}{c}0.0069 \\
(0.0083)\end{array}$ & $\begin{array}{c}0.0215 \\
(0.0423)\end{array}$ & $\begin{array}{c}0.0662 \\
(0.0432)\end{array}$ & $\begin{array}{c}0.0681 \\
(0.0432)\end{array}$ & $\begin{array}{c}0.0656 \\
(0.0430)\end{array}$ \\
\hline
\end{tabular}


TABle 4. Continued.

\begin{tabular}{|c|c|c|c|c|c|c|c|c|}
\hline \multirow[b]{3}{*}{ Black } & \multicolumn{4}{|c|}{ Smoke Dummy } & \multicolumn{4}{|c|}{ Smoke Frequency } \\
\hline & \multicolumn{2}{|c|}{ Homogeneous } & \multirow{2}{*}{$\begin{array}{c}\mathrm{ES} \\
-0.1210^{* * *} \\
(0.0138)\end{array}$} & \multirow{2}{*}{$\begin{array}{c}\mathrm{CO} \\
-0.1208^{* * *} \\
(0.0138)\end{array}$} & \multicolumn{2}{|c|}{ Homogeneous } & \multirow{2}{*}{$\begin{array}{c}\mathrm{ES} \\
-0.6000^{* * *} \\
(0.0716)\end{array}$} & \multirow{2}{*}{$\begin{array}{c}\mathrm{CO} \\
-0.6016^{\text {*** }} \\
(0.0717)\end{array}$} \\
\hline & $\begin{array}{c}-0.1203^{* * *} \\
(0.0139)\end{array}$ & $\begin{array}{c}-0.1213^{* * *} \\
(0.0139)\end{array}$ & & & $\begin{array}{c}-0.5942^{* * *} \\
(0.0732)\end{array}$ & $\begin{array}{c}-0.6013^{* * *} \\
(0.0716)\end{array}$ & & \\
\hline Hisp & $\begin{array}{l}-0.007 \\
(0.0155)\end{array}$ & $\begin{array}{c}-0.0110 \\
(0.0155)\end{array}$ & $\begin{array}{c}-0.0105 \\
(0.0155)\end{array}$ & $\begin{array}{c}-0.0108 \\
(0.0155)\end{array}$ & $\begin{array}{c}-0.0175 \\
(0.0802)\end{array}$ & $\begin{array}{c}-0.0285 \\
(0.0797)\end{array}$ & $\begin{array}{c}-0.0270 \\
(0.0797)\end{array}$ & $\begin{array}{c}-0.0294 \\
(0.0802)\end{array}$ \\
\hline Asian & $\begin{array}{c}-0.0565^{* * *} \\
(0.0197)\end{array}$ & $\begin{array}{c}-0.0695^{* * *} \\
(0.0195)\end{array}$ & $\begin{array}{c}-0.0692^{* * *} \\
(0.0195)\end{array}$ & $\begin{array}{c}-0.0692^{* * *} \\
(0.0195)\end{array}$ & $\begin{array}{c}-0.1540 \\
(0.1005)\end{array}$ & $\begin{array}{c}-0.2195^{* *} \\
(0.1017)\end{array}$ & $\begin{array}{c}-0.2129^{* *} \\
(0.1011)\end{array}$ & $\begin{array}{c}-0.2156^{* *} \\
(0.1012)\end{array}$ \\
\hline Other race & $\begin{array}{r}0.0384^{*} \\
(0.0183)\end{array}$ & $\begin{array}{c}0.0306^{*} \\
(0.0180)\end{array}$ & $\begin{array}{c}0.0312^{*} \\
(0.0181)\end{array}$ & $\begin{array}{c}0.0310^{*} \\
(0.0181)\end{array}$ & $\begin{array}{l}0.2652^{* * *} \\
(0.0949)\end{array}$ & $\begin{array}{l}0.2237^{* *} \\
(0.0973)\end{array}$ & $\begin{array}{c}0.2283^{* *} \\
(0.0935)\end{array}$ & $\begin{array}{c}0.2250^{* *} \\
(0.0938)\end{array}$ \\
\hline Prof & $\begin{array}{c}0.0124 \\
(0.0129)\end{array}$ & $\begin{array}{c}0.0155 \\
(0.0128)\end{array}$ & $\begin{array}{c}0.0158 \\
(0.0128)\end{array}$ & $\begin{array}{c}0.0162 \\
(0.0128)\end{array}$ & $\begin{array}{c}0.0189 \\
(0.0670)\end{array}$ & $\begin{array}{c}0.0337 \\
(0.0665)\end{array}$ & $\begin{array}{c}0.0314 \\
(0.0662)\end{array}$ & $\begin{array}{c}0.0342 \\
(0.0667)\end{array}$ \\
\hline Home & $\begin{array}{r}-0.0042 \\
(0.0152)\end{array}$ & $\begin{array}{r}-0.0056 \\
(0.0152)\end{array}$ & $\begin{array}{r}-0.0049 \\
(0.0151)\end{array}$ & $\begin{array}{r}-0.0047 \\
(0.0151)\end{array}$ & $\begin{array}{c}0.0181 \\
(0.0770)\end{array}$ & $\begin{array}{c}0.0126 \\
(0.0798)\end{array}$ & $\begin{array}{c}0.0116 \\
(0.0785)\end{array}$ & $\begin{array}{c}0.0118 \\
(0.0787)\end{array}$ \\
\hline Nonprof & $\begin{array}{l}0.0291^{* * *} \\
(0.0119)\end{array}$ & $\begin{array}{l}0.0284^{* * *} \\
(0.0118)\end{array}$ & $\begin{array}{l}0.0286^{* * *} \\
(0.0119)\end{array}$ & $\begin{array}{l}0.0290^{* * *} \\
(0.0119)\end{array}$ & $\begin{array}{c}0.1294^{* *} \\
(0.0628)\end{array}$ & $\begin{array}{c}0.1276^{* *} \\
(0.0622)\end{array}$ & $\begin{array}{l}0.1227^{* *} \\
(0.0617)\end{array}$ & $\begin{array}{c}0.1272^{* *} \\
(0.0612)\end{array}$ \\
\hline Contextual effect & Yes & Yes & Yes & Yes & Yes & Yes & Yes & Yes \\
\hline Group fixed effect & Yes & Yes & Yes & Yes & Yes & Yes & Yes & Yes \\
\hline$\sigma_{\varepsilon}^{2}$ & 0.1577 & 0.1551 & 0.1550 & 0.1551 & 4.2562 & 4.1819 & 4.1750 & 4.1817 \\
\hline
\end{tabular}

Note: We report the posterior mean of each parameter and the standard deviation in the parenthesis. The asterisks $* * *(* *, *)$ indicates that its $99 \%(95 \%, 90 \%)$ highest posterior density range does not cover zero. The MCMC sampling is running for 50,000 iterations with the first 5000 iterations dropped for burn-in. All cases pass the convergence diagnostics provided by Geweke (1992) and Raftery and Lewis (1992). ES: emotional stability; CO: conscientiousness. In the heterogeneous peer effect case, "high" means personality trait score above school average, and "low" means personality trait score below the school average. $A$-to- $B$ denotes the peer effect that $B$ receives from $A$. 
Adding personality measures as control variables (in column 2) does not fully account for individual correlated effects, yet may alleviate part of the omitted variable problem, and the endogenous peer effect decreases to 0.0842 (dummy) and 0.0911 (frequency), respectively. In line with the evidence discussed in Section 2.2, students who are emotionally stable and conscientious tend to smoke less. The three parent-related variables, parent smoke, low parent control, and strong maternal care, all have significant effects on their children's smoking behaviors and the signs of effects are in line with our expectation. Black and Asian students are less likely to be smokers compared to their white counterparts. Most of the contextual effects are nonsignificant (and thus not shown in the table), yet it seems that peer's extraversion has a negative effect on individual's smoking.

When studying heterogeneous peer effects (columns 3 and 4) for the binary indicator of smoking, it is found that the peer effects between two emotionally unstable individuals are strongest, with no similar findings for conscientiousness. ${ }^{15}$ However, the results for smoking frequency (columns 7 and 8) show that emotionally unstable individuals are affected by both personality types, whereas emotionally stable individuals are affected much less. Since emotionally stable peers tend to smoke less (see Table 3), the smaller estimated peer effect from high-to-low in the binary definition of smoking is therefore likely to be driven by a lower frequency of smoking among the emotionally stable peers.

These baseline findings are suggestive that emotionally unstable individuals are more affected by peers, yet may suffer from unobserved variables affecting both the outcome and friendship formation. Therefore, we turn to the extended SC-SAR model.

\subsection{The peer effects on smoking: Extended SC-SAR model}

Estimation results of the extended SC-SAR model are reported in Table 5. On basis of theoretical and empirical criterions, we focus on the cases with latent variables in four dimensions and leave other cases (with different dimensions) available upon request. The theoretical criterion we employ is the AICM (Akaike's information criterion-Monte Carlo) proposed by Raftery, Newton, Satagopan, and Krivitsky (2007). ${ }^{16}$ The empirical criterion is based on the idea that the estimates from the SC-SAR model should at some point stabilize after increasing the dimension of the latent variables. The SC-SAR(4) model is the preferred model on basis of both criterions.

We start with discussing the estimates of the link formation model in the middle panel of Table 5. The first few rows show that there is strong homophily in terms of

\footnotetext{
${ }^{15}$ We additionally investigated heterogeneity with respect to emotional stability and conscientiousness jointly, that is, defining 16 different interactions on basis of the joint occurrence of the two personality traits rather than the current four interactions on basis of the personality traits separately. The results confirm that the endogenous peer effects are universally larger and only statistically significant when the receiving student is emotionally unstable, with the magnitude of the endogenous peer effects largely unaffected by conscientiousness of the individual or his/her peers (results available upon request). Therefore, we continue to analyze the two personality traits separately.

${ }^{16} \mathrm{AICM}$ is an estimate of the conventional AIC, which is not directly obtained from the posterior simulation as the maximum log-likelihood value may not be available. Given that the distribution of the loglikelihoods from each posterior draws is approximately a gamma distribution, we can obtain an estimate of AICM as well as its standard error. Same as the conventional AIC, the model with a lower AICM value is favored.
} 
TABLE 5. Peer effects on smoking-SC-SAR models with endogenous networks and exogenous personality.

\begin{tabular}{|c|c|c|c|c|c|c|}
\hline & \multicolumn{3}{|c|}{ Smoke Dummy } & \multicolumn{3}{|c|}{ Smoke Frequency } \\
\hline & Homogeneous & ES & $\mathrm{CO}$ & Homogeneous & ES & $\mathrm{CO}$ \\
\hline \multicolumn{7}{|l|}{ Endogenous Effect } \\
\hline & $\begin{array}{l}0.0374^{* * *} \\
(0.0098)\end{array}$ & & & $\begin{array}{l}0.0715^{* * *} \\
(0.0091)\end{array}$ & & \\
\hline Low-to-low $\left(\lambda_{11}\right)$ & & $\begin{array}{l}0.0668^{* * *} \\
(0.0147)\end{array}$ & $\begin{array}{l}0.0442^{* * *} \\
(0.0174)\end{array}$ & & $\begin{array}{l}0.0904^{* * *} \\
(0.0129)\end{array}$ & $\begin{array}{l}0.0672^{* * *} \\
(0.0164)\end{array}$ \\
\hline High-to-low $\left(\lambda_{12}\right)$ & & $\begin{array}{c}0.0247 \\
(0.0191)\end{array}$ & $\begin{array}{c}0.0382^{* *} \\
(0.0181)\end{array}$ & & $\begin{array}{l}0.0854^{* * *} \\
(0.0210)\end{array}$ & $\begin{array}{l}0.0636^{* * *} \\
(0.0182)\end{array}$ \\
\hline Low-to-high $\left(\lambda_{21}\right)$ & & $\begin{array}{c}0.0316 \\
(0.0186)\end{array}$ & $\begin{array}{c}0.0357^{* *} \\
(0.0180)\end{array}$ & & $\begin{array}{c}0.0139 \\
(0.0183)\end{array}$ & $\begin{array}{l}0.0682^{* * *} \\
(0.0196)\end{array}$ \\
\hline High-to-high $\left(\lambda_{22}\right)$ & & $\begin{array}{c}0.0360^{* *} \\
(0.0183)\end{array}$ & $\begin{array}{c}0.0322^{* *} \\
(0.0152)\end{array}$ & & $\begin{array}{c}0.0304^{*} \\
(0.0186)\end{array}$ & $\begin{array}{l}0.0588^{* * *} \\
(0.0137)\end{array}$ \\
\hline Own and Contextual effect & Yes & Yes & Yes & Yes & Yes & Yes \\
\hline Group fixed effect & Yes & Yes & Yes & Yes & Yes & Yes \\
\hline$\sigma_{u}^{2}$ & 0.1341 & 0.1344 & 0.1343 & 3.5772 & 3.6319 & 3.6609 \\
\hline \multicolumn{7}{|l|}{ Link formation } \\
\hline Constant & $\begin{array}{l}1.0340^{* * *} \\
(0.0789)\end{array}$ & $\begin{array}{l}1.0395^{* * *} \\
(0.0799)\end{array}$ & $\begin{array}{l}1.0333^{* * *} \\
(0.0788)\end{array}$ & $\begin{array}{l}1.0131^{* * *} \\
(0.0813)\end{array}$ & $\begin{array}{l}1.0280^{* * *} \\
(0.0780)\end{array}$ & $\begin{array}{l}1.0370^{* * * *} \\
(0.0825)\end{array}$ \\
\hline Grade & $\begin{array}{l}2.7500^{* * *} \\
(0.0380)\end{array}$ & $\begin{array}{l}2.7533^{* * *} \\
(0.0392)\end{array}$ & $\begin{array}{l}2.7553^{* * *} \\
(0.0390)\end{array}$ & $\begin{array}{l}2.7405^{* * *} \\
(0.0381)\end{array}$ & $\begin{array}{l}2.7457^{* * *} \\
(0.0385)\end{array}$ & $\begin{array}{l}2.7509^{* * *} \\
(0.0384)\end{array}$ \\
\hline Sex & $\begin{array}{l}0.3511^{* * *} \\
(0.0342)\end{array}$ & $\begin{array}{l}0.3498^{* * *} \\
(0.0348)\end{array}$ & $\begin{array}{l}0.3506^{* * *} \\
(0.0335)\end{array}$ & $\begin{array}{l}0.3516^{* * *} \\
(0.0339)\end{array}$ & $\begin{array}{l}0.3508^{* * *} \\
(0.0347)\end{array}$ & $\begin{array}{l}0.3533^{* * *} \\
(0.0325)\end{array}$ \\
\hline Race & $\begin{array}{l}1.1213^{* * *} \\
(0.0415)\end{array}$ & $\begin{array}{l}1.1216^{* * *} \\
(0.0413)\end{array}$ & $\begin{array}{l}1.1190^{* * *} \\
(0.0403)\end{array}$ & $\begin{array}{l}1.1222^{* * *} \\
(0.0394)\end{array}$ & $\begin{array}{l}1.1175^{* * *} \\
(0.0406)\end{array}$ & $\begin{array}{l}1.1225^{* * *} \\
(0.0414)\end{array}$ \\
\hline Emotional stability & $\begin{array}{r}-0.0563^{*} \\
(0.0291)\end{array}$ & $\begin{array}{r}-0.0582^{*} \\
(0.0291)\end{array}$ & $\begin{array}{r}-0.0583^{*} \\
(0.0301)\end{array}$ & $\begin{array}{r}-0.0519^{*} \\
(0.0290)\end{array}$ & $\begin{array}{r}-0.0591^{*} \\
(0.0294)\end{array}$ & $\begin{array}{r}-0.0603^{*} \\
(0.0294)\end{array}$ \\
\hline Conscientiousness & $\begin{array}{c}-0.0410 \\
(0.0255)\end{array}$ & $\begin{array}{r}-0.0400 \\
(0.0255)\end{array}$ & $\begin{array}{c}-0.0397 \\
(0.0256)\end{array}$ & $\begin{array}{c}-0.0382 \\
(0.0257)\end{array}$ & $\begin{array}{r}-0.0380 \\
(0.0254)\end{array}$ & $\begin{array}{c}-0.0390 \\
(0.0249)\end{array}$ \\
\hline Extraversion & $\begin{array}{c}-0.2636^{* * *} \\
(0.0277)\end{array}$ & $\begin{array}{c}-0.2654^{* * *} \\
(0.0269)\end{array}$ & $\begin{array}{c}-0.2626^{* * *} \\
(0.0274)\end{array}$ & $\begin{array}{c}-0.2606^{* * *} \\
(0.0260)\end{array}$ & $\begin{array}{c}-0.2585^{* * *} \\
(0.0275)\end{array}$ & $\begin{array}{c}-0.2592^{* * *} \\
(0.0280)\end{array}$ \\
\hline$\delta_{1}$ & $\begin{array}{c}-3.4773^{* * *} \\
(0.1152)\end{array}$ & $\begin{array}{c}-3.5842^{* * *} \\
(0.1443)\end{array}$ & $\begin{array}{c}-3.4545^{* * *} \\
(0.1417)\end{array}$ & $\begin{array}{c}-3.4077^{* * *} \\
(0.1190)\end{array}$ & $\begin{array}{c}-3.5040^{* * *} \\
(0.1464)\end{array}$ & $\begin{array}{c}-3.4633^{* * *} \\
(0.1181)\end{array}$ \\
\hline$\delta_{2}$ & $\begin{array}{c}-3.2812^{* * *} \\
(0.0909)\end{array}$ & $\begin{array}{c}-3.2175^{* * *} \\
(0.1220)\end{array}$ & $\begin{array}{c}-3.2042^{* * *} \\
(0.1027)\end{array}$ & $\begin{array}{c}-3.2492^{* * *} \\
(0.0967)\end{array}$ & $\begin{array}{c}-3.2449^{* * *} \\
(0.1242)\end{array}$ & $\begin{array}{c}-3.2028^{* * *} \\
(0.0994)\end{array}$ \\
\hline$\delta_{3}$ & $\begin{array}{c}-3.0676^{* * *} \\
(0.1213)\end{array}$ & $\begin{array}{c}-2.9778^{* * *} \\
(0.1015)\end{array}$ & $\begin{array}{c}-3.0365^{* * *} \\
(0.0933)\end{array}$ & $\begin{array}{c}-3.0688^{* * *} \\
(0.0896)\end{array}$ & $\begin{array}{c}-2.9919^{* * *} \\
(0.1002)\end{array}$ & $\begin{array}{c}-3.0178^{* * *} \\
(0.0749)\end{array}$ \\
\hline$\delta_{4}$ & $\begin{array}{c}-2.7491^{* * *} \\
(0.1542)\end{array}$ & $\begin{array}{c}-2.8179^{* * *} \\
(0.0926)\end{array}$ & $\begin{array}{c}-2.8567^{* * *} \\
(0.1115)\end{array}$ & $\begin{array}{c}-2.7767^{* * *} \\
(0.1401)\end{array}$ & $\begin{array}{c}-2.8162^{* * *} \\
(0.1253)\end{array}$ & $\begin{array}{c}-2.8984^{* * *} \\
(0.0856)\end{array}$ \\
\hline AICM & 116,060 & 118,330 & 121,290 & 148,790 & 153,940 & 146,560 \\
\hline$s e(A I C M)$ & 3749 & 3887 & 4063 & 3280 & 3849 & 3944 \\
\hline
\end{tabular}

Note: We report the posterior mean of each parameter and the standard deviation in the parenthesis based on the SCSAR(4) model. The asterisks $* * *(* *, *)$ indicates that its $99 \%(95 \%, 90 \%)$ highest posterior density range does not cover zero. The MCMC sampling is running for 250,000 iterations with the first 100,000 iterations dropped for burn-in. All cases pass the convergence diagnostics provided by Geweke (1992) and Raftery and Lewis (1992). ES: emotional stability; CO: conscientiousness. In the heterogeneous peer effect case, "high" means personality trait score above school average, and "low" means personality trait score below the school average. $A$-to- $B$ denotes the peer effect that $B$ receives from $A$. 
grade, sex, and race: individuals in the same grade, and of the same sex and race tend to nominate each other as friends. This is reassuring, since these variables help identifying the endogenous friendship formation, and are naturally excluded from the outcome equation. ${ }^{17}$ The results further show that students are less likely to hang out together if they have different levels of extraversion. Differences in emotional stability also affect friendship formations, where the coefficients are on the margin of being significant. The difference in conscientiousness levels does not seem to matter.

The top panel of Table 5 shows the endogenous peer effects in smoking. For the homogenous endogenous peer effect on the binary indicator of smoking, the estimate equals 0.0374 , suggesting that on average, when a friend starts smoking, you are 3.74 percentage points more likely to start smoking. With a baseline smoking prevalence of $22 \%$, this is equivalent to an effect size of $17 \%$. The estimate for smoking frequency is 0.0715 , which equals an effect size of $8 \%$ given an average smoking frequency of 0.9 days a week. The SC-SAR estimates are much smaller than the estimates obtained from the SAR model, and lower than most of the peer effects estimated in the literature. Hsieh and Lee (2016) reported a similar percentage of bias correction in the SC-SAR model when studying student's academic performance as the dependent variable. Taken together, this suggests that the conventional SAR model erroneously assumes that the spatial weight matrix is exogenously given, and overestimates endogenous peer effects substantially.

The heterogeneous peer effects are presented in the remaining columns of Table 5. It can be observed that although the magnitude of the coefficients becomes smaller compared to Table 4, the same pattern across peers of different personalities remains. Individuals who are emotionally unstable are influenced much more in terms of smoking compared with emotionally stable individuals. Interestingly, for conscientiousness this is not the case. In fact, moving across rows suggest that the heterogeneity in peer effects with respect to conscientiousness is very modest, and all interactions are close to the average (homogenous) peer effect. The statistical significance of these differences can be assessed from the posterior density plots in Figures 2 and 3. And, slightly abusing the Bayesian paradigm, we also use the posterior distributions to compute conventional Wald tests on the homogeneity of the parameters in Table 6 .

As expected from the results in Table 5, the top panel of Table 6 shows that we cannot reject homogeneity of the endogenous peer effects in any case with respect to conscientiousness. We can reject homogeneity of the endogenous peer effects for the smoking frequency outcome with respect to emotional stability, but not for the binary smoking indicator. For the smoking frequency outcome, the individual tests indicate that when the receiving individual is emotionally unstable $\left(\lambda_{11}\right.$ and $\left.\lambda_{12}\right)$, the endogenous peer effects are significantly different from the case where the receiving individual is emotionally stable $\left(\lambda_{21}\right.$ and $\left.\lambda_{22}\right)$. This provides strong evidence that for smoking frequency, the peer effects are heterogeneous, with emotionally unstable individuals significantly more

\footnotetext{
${ }^{17}$ The individual's own grade, race, and gender, and the average grade, race, and gender of his/her friends may still affect the smoking decision, but we assume that the dyad specific pairs (e.g., individual $i$ and $j$ share the same sex and race) do not affect individual's $i$ smoking decision. We present further evidence on this assumption in Section 6.4 below.
} 

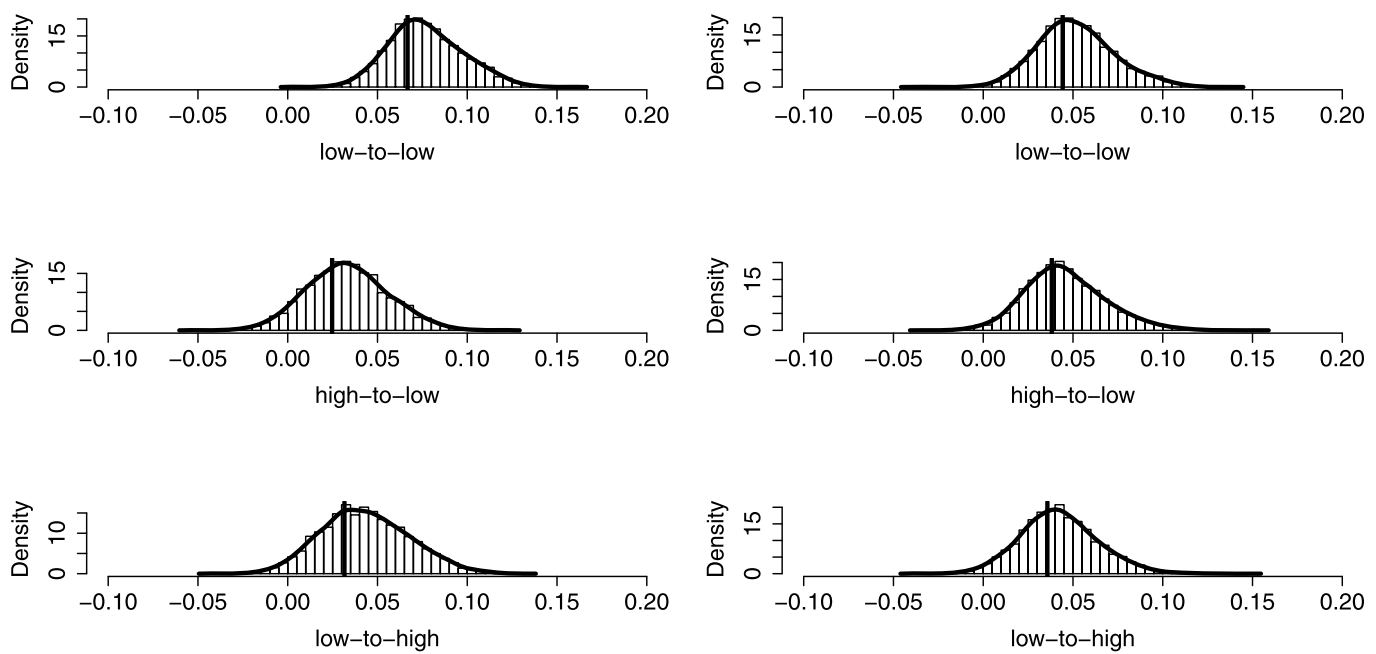

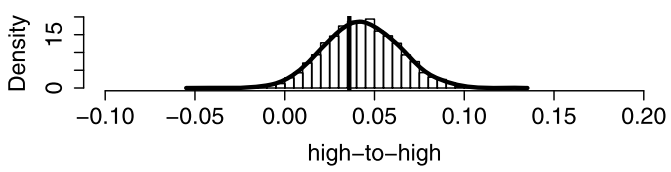

(a) Emotional Stability

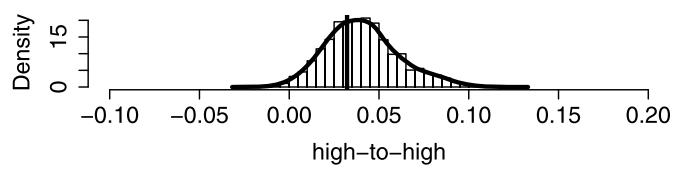

(b) Conscientiousness

FIgURE 2. Posterior distributions of endogenous peer effects on smoking dummy. The prior distribution is uniformly distributed between -1 and 1 . The posterior mean is indicated by the black vertical line. "High" means personality trait score above school average, and "low" means personality trait score below the school average. $A$-to- $B$ denotes the peer effect that $B$ receives from $A$.

vulnerable to peer effects. For the binary smoking indicator, the Wald tests provide tentative evidence at a $10 \%$ significance level that the interactions between two emotionally unstable individuals $\left(\lambda_{11}\right)$ are significantly different from the others, but here we lack the statistical power to formally reject equivalence of the coefficients at a conventional level of significance. Indeed, in the bottom panel of Table 6 we compute Wald tests on basis of the larger in-school survey (cf. the final two columns of the supplementary Appendix Table A.9), and here we can clearly reject the joint test that all endogenous peer effects are homogenous for both the smoking dummy and smoking frequency. Taken together, we think these tests provide convincing evidence that heterogeneity in peer effects exists with respect to emotional stability.

In Figure 4, we plot the distribution of the social multiplier effects based on Table 5. The social multiplier is the predicted total impact of an individual starting smoking, taking into account both the direct own effect and the indirect effect running through the impact on his/her peers, and hence is always larger than or equal to $1 .^{18}$ The figure shows the social multipliers separately for groups of emotionally stable and emotionally unsta-

\footnotetext{
${ }^{18}$ The social multipliers are calculated by the formula $\left(I_{m_{g}}-\lambda_{11} W_{11, g}-\cdots-\lambda_{22} W_{22, g}\right)^{-1} \ell_{g}, g=1, \ldots, G$.
} 

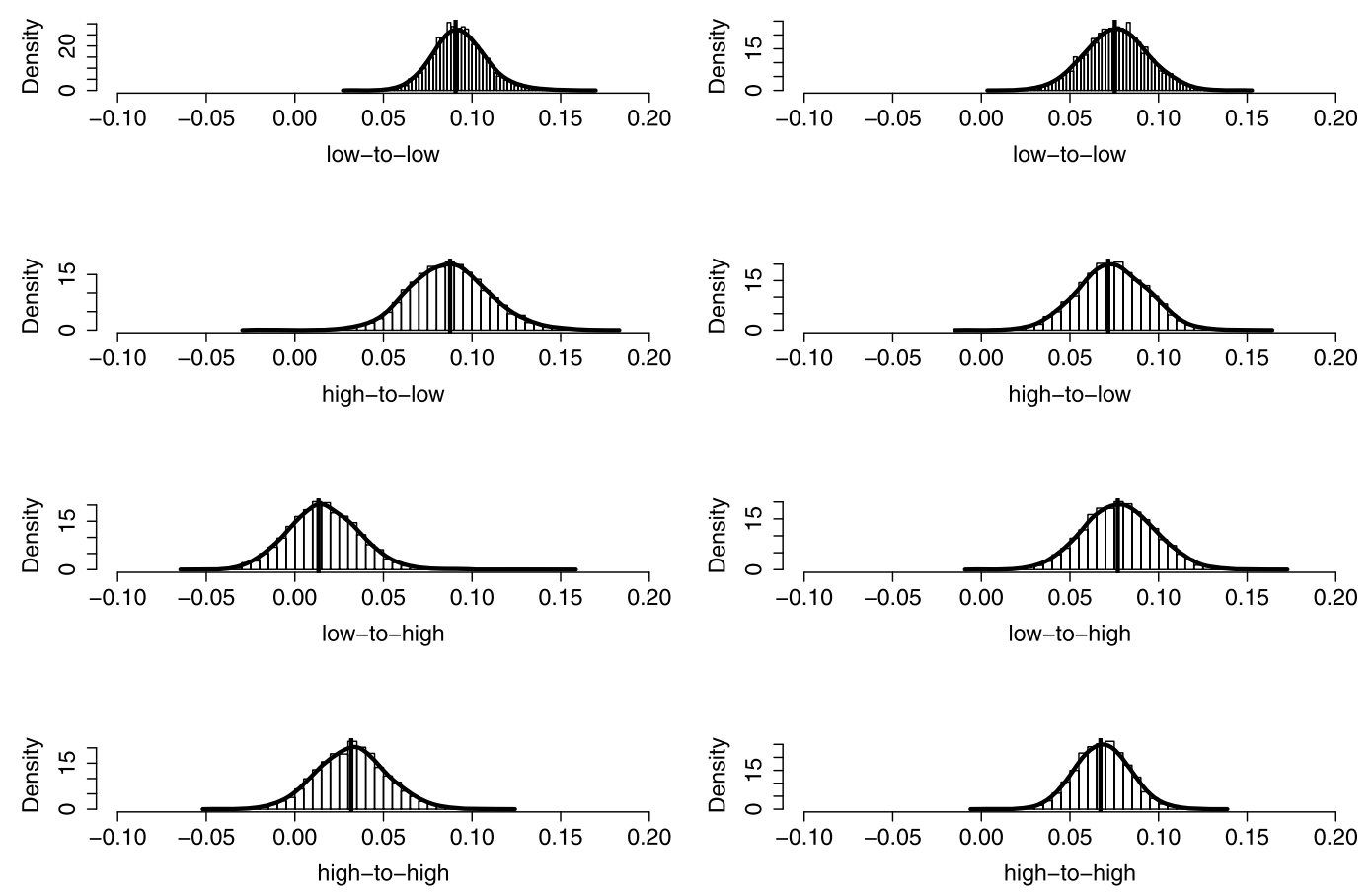

(a) Emotional Stability

(b) Conscientiousness

FiguRE 3. Posterior distributions of endogenous peer effects on smoking frequency. The prior distribution is uniformly distributed between -1 and 1 . The posterior mean is indicated by the black vertical line. "High" means personality trait score above school average, and "low" means personality trait score below the school average. $A$-to- $B$ denotes the peer effect that $B$ receives from $A$.

ble personalities. In line with the point estimates, one can see that the emotionally unstable students generally experience larger multiplier effects than the emotionally stable students. It should be acknowledged however that these multiplier effects are likely to be a lower bound on the true multipliers since not all friends are observed in the in-home survey.

\section{Robustness CHecks}

In this section, we present a number of robustness checks, results of which can be found in the supplementary Appendix A.

\subsection{Measurement of personality}

When stratifying the sample on basis of personality, one may be worried that personality is endogenous. This could be either because one's personality is affected by the peer group, or since personality is correlated to unobserved variables that also affect the outcome. In this section, we will investigate the robustness of our results by treat- 
TABLE 6. Wald tests on homogeneity of peer effects-SC-SAR model.

\begin{tabular}{|c|c|c|c|c|}
\hline & \multicolumn{2}{|c|}{ Smoke Dummy } & \multicolumn{2}{|c|}{ Smoke Frequency } \\
\hline & ES & $\mathrm{CO}$ & ES & $\mathrm{CO}$ \\
\hline \multicolumn{5}{|c|}{ In-home main sample } \\
\hline All $\lambda_{i j}$ 's are equal & 0.4109 & 0.9900 & 0.0007 & 0.9975 \\
\hline$\lambda_{11}=\lambda_{12}$ & 0.0821 & 0.8121 & 0.9041 & 0.8919 \\
\hline$\lambda_{11}=\lambda_{21}$ & 0.0590 & 0.6763 & 0.0000 & 0.9674 \\
\hline$\lambda_{11}=\lambda_{22}$ & 0.1492 & 0.5609 & 0.0067 & 0.6839 \\
\hline$\lambda_{12}=\lambda_{21}$ & 0.8043 & 0.9264 & 0.0167 & 0.8809 \\
\hline$\lambda_{12}=\lambda_{22}$ & 0.6299 & 0.7551 & 0.0335 & 0.8140 \\
\hline$\lambda_{21}=\lambda_{22}$ & 0.8683 & 0.8792 & 0.4903 & 0.7031 \\
\hline \multicolumn{5}{|l|}{ In-school sample } \\
\hline All $\lambda_{i j}$ 's are equal & 0.0004 & & 0.0000 & \\
\hline$\lambda_{11}=\lambda_{12}$ & 0.0000 & & 0.0109 & \\
\hline$\lambda_{11}=\lambda_{21}$ & 0.0052 & & 0.0000 & \\
\hline$\lambda_{11}=\lambda_{22}$ & 0.0000 & & 0.0000 & \\
\hline$\lambda_{12}=\lambda_{21}$ & 0.0256 & & 0.0072 & \\
\hline$\lambda_{12}=\lambda_{22}$ & 0.5918 & & 0.0040 & \\
\hline$\lambda_{21}=\lambda_{22}$ & 0.0448 & & 0.8325 & \\
\hline
\end{tabular}

Note: Values reported in the table are associated $p$-values for the test specified, on the basis of the main in-home sample estimates (estimates can be found in Table 5) and on the basis of the in-school sample (estimates can be found in last two columns of Appendix Table A.9). ES: emotional stability; CO: conscientiousness. $\lambda_{11}$ presents the peer effects when both individuals have personality trait scores below the average, $\lambda_{12}$ represents peer effects from individuals with above-average to individuals with below-average personality trait scores, $\lambda_{21}$ presents peer effects from individuals with above-average to individuals with below-average personality trait scores, and $\lambda_{22}$ presents peer effects where both individuals have above-average personality trait scores.

ing personality as being endogenously determined. We will do so by introducing an additional equation in which personality is endogenously determined, and we allow the unobserved latent variables to additionally influence personality, apart from their influence on friendship decisions and smoking. Ideally one would like to model the decisions regarding personalities and network links as a general simultaneous equation system, in which personality affects friendship decisions, and friends in turn may affect each other's personalities. However, no exogenous instrumental variables for either personality or network links are available, and so the simultaneous equation system is not identified. Instead, we consider two alternative restrictions on the simultaneous equations that permit identification.

In the first approach, endogenous personalities are allowed to affect friendship decisions, but we restrict the endogenous peer effect (i.e., the effect operating through network links) on personality to be zero. This seems a reasonable assumption given the large genetic component of conscientiousness and emotional stability (Bouchard (1994), Bouchard and Loehlin (2001)). Accordingly, individual's $r$ th personality is modeled by a simple linear regression without an endogenous peer effect or contextual effects,

$$
s_{i r, g}=x_{i, g} \phi_{1 r}+z_{i, g} \tau_{1 r}+\kappa_{r, g}+v_{i r, g}, \quad v_{i r, g} \sim \mathcal{N}\left(0, \sigma_{v_{r}}^{2}\right),
$$



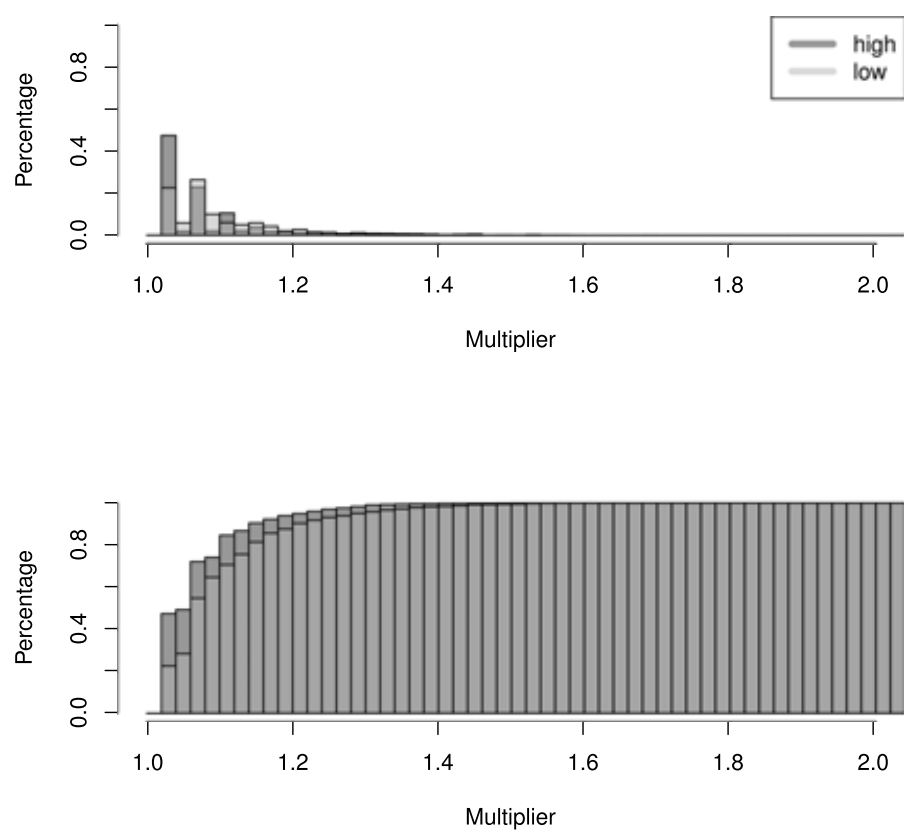

(a) Smoke dummy
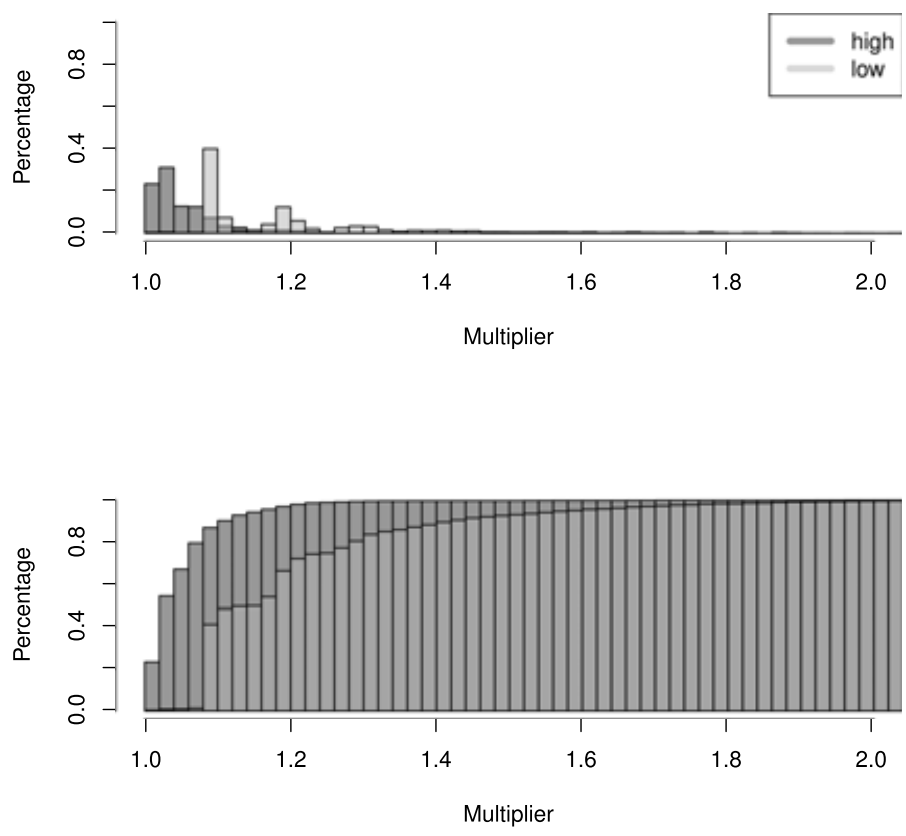

(b) Smoke frequency

FIgURE 4. Distributions of multiplier effects on smoking by emotional stability groups. Students without friendship links are excluded. "High" means personality trait score above school average, and "low" means personality trait score below the school average. 
where $\kappa_{r, g}$ stands for the group correlated effect for personality, and recall that $z_{i, g}$ captures the latent variables that additionally influence the friendship and smoking decisions.

In the second approach, we allow for endogenous peer effects in personality, yet assume that the effect of personality on friendship formation is zero. The corresponding equation for endogenous personality is specified as

$$
\begin{aligned}
s_{i r, g}= & \rho_{r} \sum_{j \neq i} w_{i j, g} s_{j r, g}+x_{i, g} \phi_{1 r}+\sum_{j \neq i} w_{i j, g} x_{j, g} \phi_{2 r}+z_{i, g} \tau_{1 r} \\
& +\sum_{j \neq i} w_{i j, g} z_{j, g} \tau_{2 r}+\kappa_{r, g}+v_{i r, g}, \quad v_{i r, g} \sim \mathcal{N}\left(0, \sigma_{v_{r}}^{2}\right),
\end{aligned}
$$

where personality is potentially influenced by friendship networks though endogenous and contextual peer effects. We estimate equations (6) and (7) for both personality measures, along with the SC-SAR extension of smoking outcome in equation (5) and the link formation model in equation (4).

The results based on equation (6) are in Appendix Table A.3. The most important observation is that the endogenous peer effects are very similar to our baseline results in Table 5, and if anything the endogenous peer effects are larger when the potential endogeneity of personality is taken into account. Also, our main finding that the social interactions for emotionally unstable individuals are most important holds up in the setting with endogenous personality.

The results based on equation (7) in Appendix Table A.4 reassuringly show that emotional stability and conscientiousness are not affected by peers. Note that extraversion is endogenously affected by peers, which was our reason for not stratifying the sample on basis of extraversion. Again, when treating personality as being endogenously determined, the estimates of endogenous peer effects from the SC-SAR model if anything become larger after endogenizing personalities, and the interactions between emotionally unstable individuals produce the largest peer effects. Overall, we conclude that the possible endogeneity of personality is not driving our results.

Apart from the endogeneity of personality, one may be worried that our dichotomization into personality types is arbitrary. We have stratified the sample into two personality types on basis of the school average since one school represents one network, and stratifying by the school average then ensures a roughly equal division of students into below average and above average personality scores in each network. However, an alternative stratification of personality types could be on basis of the sample average. In Appendix Table A.5, the results are presented where we stratify personality into two types on the basis of the overall sample average rather than the school average. It turns out that the results are very similar to our baseline case.

We have additionally estimated a model with linear interaction terms between the peer effect and personality. That is, instead of the dichotomization from equation (1), we estimate

$$
y_{i, g}=\lambda_{1} \sum_{j \neq i} w_{i j, g} y_{j, g} s_{i, g}+\lambda_{2} \sum_{j \neq i} w_{i j, g} y_{j, g} s_{j, g}+\lambda_{3} \sum_{j \neq i} w_{i j, g} y_{j, g} s_{i, g} s_{j, g}+\cdots,
$$


where we abbreviate all control variables by dots for notational simplicity. Since the personality variables have mean zero, the interpretation of $\lambda_{1}$ is the extent to which the peer effect from the average peer varies with one's own personality, $\lambda_{2}$ is the extent to which the peer effect for the average individual varies with the peer's personality, and $\lambda_{3}$ measures whether there is an additional effect if the individual and his/her peer have similar personalities.

Appendix Table A.6 shows that statistical significance varies depending on the outcome studied, yet the point estimates point in the same direction. The peer effect is stronger (i) for emotionally unstable individuals, (ii) for emotionally unstable peers, and (iii) if the individual and his/her peer are both emotionally stable or both emotionally unstable (similar personality). For both outcomes, it is consistently the individual's own emotional stability that significantly determines the peer effect. For conscientiousness, the interaction terms are mostly insignificant, except for $\lambda_{3}$ in the case of smoking frequency. These results suggest that our results are not driven by the dichotomization of personality, and also hold for a model with linear interaction terms.

\subsection{Spatial weight matrix and missing network links}

In our main specification, we chose to use the raw spatial weight matrix instead of the row-normalized matrix. Here, we present the estimates using the row-normalized matrix, where we normalize each of the four blocks of the spatial weight matrix separately. In the row-normalized case, the sum of each row in the block of the spatial weight matrix equals one. Hence, the resulting coefficients are the total endogenous peer effects and are not influenced by the number of friends in each block. Appendix Table A.7 presents the results. Not surprisingly, the estimated endogenous peer effects are somewhat larger compared with our main results, since we do not have to multiply the coefficients by the number of friends in each block. Still, the pattern is highly similar to our baseline results: for conscientiousness, there is very little heterogeneity, whereas emotionally unstable individuals are much more susceptible to peer effects than their emotionally stable counterparts.

A concern in using the in-home survey for our main analysis is the missing links problem (Chandrasekhar and Lewis (2011), Liu (2013)). That is, not all nominated friends from the in-school survey were selected for the in-home interview, and so the friendship network matrix is not complete. This could potentially result in biased estimates of the endogenous peer effect. Our initial focus on the in-home survey stems from the fact that the questions on conscientiousness are not available in the in-school survey. Moreover, the in-school survey does not include potentially important control variables like how much control parents exert and self-reported relationships with parents. There is a so-called saturated sample available that does include those variables and the full network, yet this sample is considerably smaller than the in-home sample (705 students in the saturated sample compared with 9728 students in the in-home sample).

To gauge the missing link problem, we rerun the analysis using two different samples for which we do observe the entire friendship network: (i) the in-school sample, and (ii) the saturated sample of schools for which all students were interviewed at home. There are two issues however in the comparison. First, the in-school survey is consider- 
ably larger than the in-home survey, and since the friendship network matrix spans the entire school, including large schools brings up computational issues. For this reason, we select only schools in the in-home survey that have a more modest size, such that for this subsample moving to the in-school sample and including the complete friendship network does not impose a too heavy computational burden. Second, the in-school survey lacks some potentially important control variables. For this reason, the direct comparison between the in-school and in-home samples reflects the combination of missing links and missing control variables. Therefore, to judge the influence of missing links as clean as possible, we also estimate a model on basis of the in-home survey but excluding the control variables that are not available in the in-school survey. Appendix Table A.8 compares the different samples in terms of student characteristics. There are some small differences but these are mostly small and statistically insignificant.

Appendix Table A.9 presents our peer effects estimates stratified by emotional stability. For the saturated sample, the average endogenous peer effect is statistically insignificant, yet our result that students who are both emotionally unstable are affecting each other most, is strongly confirmed. Comparing columns 2 and 3 suggest that excluding the control variables slightly increases the endogenous peer effects, as expected. Comparing columns 3 and 4 it follows that the endogenous peer effects in the in-school survey (without missing links) are often slightly larger than the ones in the in-home survey (with missing links). Apart from the low-to-high interactions, the results are however very similar and not significantly different. Most importantly, our main conclusion that the emotionally unstable individuals are most heavily affected by peer effects is also apparent in the in-school survey. Taken together, these results suggest that missing links may lead to a small bias in the estimates, yet are unlikely to materially affect our conclusions.

\subsection{Placebo test}

Even though it is impossible to test directly whether our extended SC-SAR has solved all endogeneity issues completely, simulation results suggest that a SC-SAR model performs well in eliminating sources of correlated effects (Hsieh and Lee (2016)). Here, we use a placebo test to present complementary evidence that our extended SC-SAR model is able to deal with some of the most notorious sources of correlated effects.

The idea is as follows. We pick an outcome measure for which, realistically, the endogenous peer effect is zero. An example is the father's education: it is highly unlikely that the educational level of the father of your peers is going to affect your own father's educational level. Hence, we expect no endogenous peer effect. Nonetheless, it is perceivable that your own father's educational level and the father's educational level of your peers are correlated, since you may select your peers on basis of social background, of which father's education is one proxy. Hence, in model specifications where individual correlated effects are not sufficiently accounted for, one is likely to find a spurious endogenous peer effect of father's education.

Indeed, in the regular SAR model (see the first three columns of Appendix Table A.10) the endogenous peer effect is estimated to be positive and statistically significant for father's education. This strongly suggests that the regular SAR model does not fully take 
into account individual correlated effects, even when group fixed effects, observed individual characteristics, and contextual effects, are controlled for (cf. columns 1-3 of Appendix Table A.10).

The idea of our extended SC-SAR model is to account for unobserved factors that correlate with both the outcome and the selection of peers. When adding dimensions of unobserved factors, we expect the extended SC-SAR model to approach the true endogenous peer effect of zero. It can be seen that correlated effects can be persistent, since even in the SC-SAR model with a one-dimensional latent factor (as in GoldsmithPinkham and Imbens (2013)), there is evidence for an endogenous peer effect of father's education. When increasing the dimension of the latent factors (moving from column 4 to 8 in Appendix Table A.10), the effect becomes statistically insignificant. In line with the evidence from simulations of Hsieh and Lee (2016), it takes multidimensional latent factors to overcome the issue of correlated effects. This suggests that, in contrast to the standard SAR model, a higher-dimensional SC-SAR model is capable of dealing with some of the most notorious and persistent sources of correlated effects.

\subsection{Exclusion restriction}

In the link formation equation (4), the dyad-specific variables-dummy indicators whether $i$ and $j$ are same sex, race, and grade-are used as exclusion restrictions. Given that these variables are defined for each $i, j$ cell (or dyad) in the friendship formation matrix, whereas the outcome is defined for each individual $i$, we argued that the dyadspecific variables can naturally be excluded from the outcome equation due to the different level of aggregation.

Nonetheless, it may be the case that the aggregate differences in characteristics (grade, sex, race, personality) compared with one's friends directly influence the outcome. This would not directly invalidate our identification, yet would go against the spirit of the exclusion restriction. As an informal check of the exclusion restriction, we additionally included (i) the sum of the dyad-specific variables per individual (i.e., the count of the same gender, race, and grade friends), and (ii) the aggregate difference in personality of individual $i$ compared with all friends $j$, in our outcome equation. That is, for the homogenous peer effect model, we replace the outcome equation

$$
\begin{aligned}
y_{i, g}= & \lambda \sum_{j \neq i} w_{i j, g} y_{j, g}+x_{i, g} \beta_{1}+\sum_{j \neq i} w_{i j, g} x_{i, g} \beta_{2}+s_{i, g} \beta_{3}+\sum_{j \neq i} w_{i j, g} s_{j, g} \beta_{4} \\
& +z_{i, g} \delta_{1}+\sum_{j \neq i} w_{i j, g} z_{j, g} \delta_{2}+\alpha_{g}+u_{i, g}
\end{aligned}
$$

by the outcome equation

$$
\begin{aligned}
y_{i, g}= & \lambda \sum_{j \neq i} w_{i j, g} y_{j, g}+x_{i, g} \beta_{1}+\sum_{j \neq i} w_{i j, g} x_{i, g} \beta_{2}+s_{i, g} \beta_{3}+\sum_{j \neq i} w_{i j, g} s_{j, g} \beta_{4} \\
& +\sum_{j \neq i} w_{i j, g} c_{i j, g} \beta_{5}+\sum_{j \neq i} w_{i j, g}\left|s_{i, g}-s_{j, g}\right| \beta_{6}+z_{i, g} \delta_{1}+\sum_{j \neq i} w_{i j, g} z_{j, g} \delta_{2}+\alpha_{g}+u_{i, g},
\end{aligned}
$$

where $c_{i j, g}$ includes the dyad-specific variables sex, race, and grade. 
The results are presented in Appendix Table A.11, and indicate that none of the aggregate differences in characteristics between the individual and his/her friends influences the outcome. Moreover, the point estimates for the homogenous peer effect are very close to our main specification. Even if not a formal proof of the exclusion restriction, this does suggest that the aggregate difference in characteristics between the individual and his/her friends has a limited direct influence on smoking decisions.

\subsection{Other health behaviors}

Our binary definition of smoking arbitrarily classifies individuals who smoke at least once a month as smokers. Here, we investigate the robustness to this definition, by using a more restrictive definition of smokers as those smoking at least once per week. The results are very similar to our main definition (see Appendix Table A.12).

The final robustness check is to study how specific results are for the case of smoking. Smoking is known to (i) severely affect health, (ii) be related to personality, and (iii) be vulnerable to peer pressure and, therefore, represents an excellent outcome of our study. Nonetheless, if our results are specific to smoking, this would limit the moderating role of personality in general social interactions. Therefore, we estimated the same set of models for another health behavior that is known to affect health and to be vulnerable to peer pressure: the prevalence of getting drunk.

In Appendix Table A.12, we present the homogenous and heterogeneous peer effects on getting drunk. The average peer effects are slightly smaller for getting drunk than for smoking, in particular given the higher prevalence of getting drunk versus smoking ( $31 \%$ vs. $22 \%$ ). Nonetheless, we observe a very similar pattern when stratifying the sample with respect to personality. The interactions between two individuals who are both emotionally unstable are most vulnerable to peer effects, whereas the other interactions are closer to the average peer effect. This suggests that the vulnerability of social interactions among emotionally unstable individuals is not specific to smoking, but a general finding that exists across a wider set of unhealthy behaviors. ${ }^{19}$

\section{Discussion}

We used friendship nominations from the Add Health data to study peer effects in smoking; in particular, whether peer effects are weaker among emotionally stable and conscientious individuals. We extended the SAR model to (i) correct for the endogeneity of the spatial weight matrix, (ii) estimate heterogeneity in peer effects, and (iii) allow for unobserved contextual effects. Our results suggest that the conventional SAR model overestimates endogenous peer effects, yet that our extended SC-SAR model provides a promising method for studying homogenous and heterogeneous peer effects. Our main conclusion is that an individual's personality plays a very important role in social interactions, and it does so along two main dimensions.

\footnotetext{
${ }^{19}$ We also studied the frequency of exercise, but could not reject a zero average effect. This suggests that peer effects are more important for unhealthy behaviors than for healthy behaviors.
} 
First, the average peer effect masks considerable heterogeneity in responses with respect to personality. Even though the average peer effect in smoking is nonnegligible, it is particularly pronounced within certain subgroups of students. We show that the individual personality trait of emotional stability is an important moderator of peer effects. Emotionally unstable students are significantly more vulnerable to peer effects than emotionally stable students. Despite being an important driver of smoking decisions, we find no evidence that conscientiousness plays a similar role in social interactions.

Second, apart from moderating the vulnerability to peer effects, personality also plays a role in friendship formation: individuals with similar personalities are more likely to hang out with each other. This is consistent with Girard, Hett, and Schunk (2015), and studies in social psychology (Cohen and Prinstein (2006), Allen et al. (2012)) that suggest that even though generally people value the opinion of high-status or popular peers, not all adolescents desire identification with high-status peers. Instead, they will adopt a local set of norms that may be more salient to these adolescent's identity development.

These two findings suggest a potentially harmful cycle in which emotionally unstable individuals are more likely to smoke in the first place, are likely to hang out with other emotionally unstable individuals, and in turn lack the skills to stand up against the peer pressure of initiating/continuing smoking. This pattern is not restricted just to smoking, but also holds for the prevalence of getting drunk. Hence, the benefits of personality traits such as emotional stability in social interactions provide a promising mechanism through which personality affects health behavior, and potentially even socioeconomic life outcomes.

In terms of policy implications, policy makers and teachers should at least realize the dominant role that personality plays in social interactions. On the positive side, our findings suggest multiple options for breaking the cycle between personality and peer pressure. One difficult but rewarding option could simply be to train emotional stability in early childhood programs, and evidence shows this can be effective at young ages (Heckman (2000)). Second, one could try to target emotionally unstable students in high school and teach them skills to stand up against peer pressure. Finally, one could try to mix students more on basis of personality to avoid groups of students who are all emotionally unstable. In many cases, subgroups in school are formed on basis of cognitive skills, but there is no reason why that could not be done on basis of noncognitive skills. We should acknowledge however that our effects are estimated on basis of the current classroom composition, and people are likely to respond to the new situation (Graham, Imbens, and Ridder (2010), Carrell, Sacerdote, and West (2013), Fruehwirth (2014)).

\section{REFERENCES}

Allen, J. P., J. Chango, D. Szwedo, M. Schad, and E. Marston (2012), "Predictors of susceptibility to peer influence regarding substance use in adolescence." Child Development, 83, 337-350. [826, 856] 
Almlund, M., A. L. Duckworth, J. Heckman, and T. Kautz (2011), "Personality psychology and economics.” In Handbook of the Economics of Education, Vol. 4. [826, 832]

Angrist, J. D. (2014), “The perils of peer effects.” Labour Economics, 30, 98-108. [827]

Arcidiacono, P., G. Foster, N. Goodpaster, and J. Kinsler (2012), "Estimating spillovers using panel data, with an application to the classroom." Quantitative Economics, 3, 421470. [827, 828]

Argys, L. M. and D. I. Rees (2008), "Searching for peer group effects: A test of the contagion hypothesis.” The Review of Economics and Statistics, 90, 442-458. [830]

Badev, A. (2017), “Discrete games in endogenous networks: Equilibria and policy.” Arxiv: 1705.03137. [826, 839]

Ballester, C., A. Calvó-Armengol, and Y. Zenou (2006), “Who’s who in networks. Wanted: The key player." Econometrica, 74, 1403-1417. [837]

Bernheim, B. Douglas, and A. Rangel (2004), "Addiction and cue-triggered decision processes." American Economic Review, 94, 1558-1590. [831]

Borghans, L., A. L. Duckworth, J. J. Heckman, and B. ter Weel (2008), “The economics and psychology of personality traits.” Journal of Human Resources, 43, 972-1059. [826, 832, 833]

Bouchard, T. J. Jr. (1994), “Genes, environment, and personality.” Science, 264, 17001701. [849]

Bouchard, T. J. Jr. and J. C. Loehlin (2001), “Genes, evolution, and personality.” Behavior Genetics, 31, 243-273. [849]

Boucher, V., Y. Bramoullé, H. Djebbari, and B. Fortin (2014), "Do peers affect student achievement? Evidence from Canada using group size variation.” Journal of Applied Econometrics, 29, 91-109. [828]

Bowles, S. and H. Gintis (1976), Schooling in Capitalist America, Vol. 57. Basic Books, New York. [831]

Bramoullé, Y., H. Djebbari, and B. Fortin (2009), "Identification of peer effects through social networks.” Journal of Econometrics, 150, 41-55. [827, 837]

Brechwald, W. A. and M. J. Prinstein (2011), "Beyond homophily: A decade of advances in understanding peer influence processes.” Journal of Research on Adolescence, 21, 166179. [830]

Brown, B., J. P. Bakken, S. W. Ameringer, and S. D. Mahon (2008), "A comprehensive conceptualization of the peer influence process in adolescence." In Understanding Peer Influence in Children and Adolescents (M. J. Prinstein and K. A. Dodge, eds.), 17-44, The Guilford Press. [830, 832]

Campbell, F., G. Conti, J. J. Heckman, S. H. Moon, R. Pinto, E. Pungello, and Y. Pan (2014), "Early childhood investments substantially boost adult health." Science, 343, 1478-1485. [826] 
Card, D. and L. Giuliano (2013), "Peer effects and multiple equilibria in the risky behavior of friends.” Review of Economics and Statistics, 95, 1130-1149. [827, 830, 837, 841]

Carrell, S. E., B. I. Sacerdote, and J. E. West (2013), "From natural variation to optimal policy? The importance of endogenous peer group formation.” Econometrica, 81, 855882. [827, 856]

Cawley, J. and C. J. Ruhm (2011), “The economics of risky health behaviors.” In Handbook of Health Economics (T. G. Mcguire, M. V. Pauly, and P. P. Barros, eds.), Handbook of Health Economics, Vol. 2, 95-199, Elsevier. [826, 829]

Chaloupka, F. J. and K. E. Warner (2000), “The economics of smoking.” In Handbook of Health Economics. Part B. Chapter 29, Vol. 1. (A. J. Culyer and J. P. Newhouse, eds.), 15391627, Elsevier. [825, 826]

Chandrasekhar, A. and R. Lewis (2011), “Econometrics of sampled networks.” Unpublished manuscript, MIT.[422]. [852]

Chiteji, N. (2010), “Time preference, noncognitive skills and well being across the life course: Do noncognitive skills encourage healthy behavior?" American Economic Review, 100, 200-204. [831]

Christakis, N. A. and J. H. Fowler (2008), “The collective dynamics of smoking in a large social network.” New England Journal of Medicine, 358, 2249-2258. [830]

Clark, A. E. and Y. Lohéac (2007), “'It wasn't me, it was them!' Social influence in risky behavior by adolescents.” Journal of Health Economics, 26, 763-784. [830, 841]

Cobb-Clark, D. A., S. C. Kassenboehmer, and S. Schurer (2014), "Healthy habits: The connection between diet, exercise, and locus of control." Journal of Economic Behavior \& Organization, 98, 1-28. [831]

Cohen, G. L. and M. J. Prinstein (2006), "Peer contagion of aggression and health risk behavior among adolescent males: An experimental investigation of effects on public conduct and private attitudes." Child Development, 77, 967-983. [856]

Cohen-Cole, E. and J. M. Fletcher (2008a), "Detecting implausible social network effects in acne, height, and headaches: Longitudinal analysis.” BMJ, 337. [830]

Cohen-Cole, E. and J. M. Fletcher (2008b), "Is obesity contagious? Social networks vs. environmental factors in the obesity epidemic.” Journal of Health Economics, 27, 13821387. [830]

Conrad, K. M., B. R. Flay, and D. Hill (1992), "Why children start smoking cigarettes: Predictors of onset.” British Journal of Addiction, 87, 1711-1724. [829]

Conti, G. and C. Hansman (2013), "Personality and the education-health gradient: A note on 'Understanding differences in health behaviors by education'." Journal of Health Economics, 32, 480-485. [833]

Conti, G., J. Heckman, and S. Urzua (2010), “The education-health gradient.” American Economic Review, 100, 234-238. [833] 
Costa, P. T. and R. R. McCrae (1992), "Normal personality assessment in clinical practice: The NEO personality inventory.” Psychological Assessment, 4, 5. [828]

Cutler, D. M. and E. L. Glaeser (2010), “Social interactions and smoking.” In Research Findings in the Economics of Aging, 123-141, University of Chicago Press. [826, 829, 830]

Danaei, G., E. L. Ding, D. Mozaffarian, B. Taylor, J. Rehm, C. J. L. Murray, and M. Ezzati (2009), "The preventable causes of death in the United States: Comparative risk assessment of dietary, lifestyle, and metabolic risk factors." PLoS medicine, 6, e1000058. [825]

Deary, I. J., A. Weiss, and G. D. Batty (2010), “Intelligence and personality as predictors of illness and death: How researchers in differential psychology and chronic disease epidemiology are collaborating to understand and address health inequalities." Psychological Science in the Public Interest, 11, 53-79. [831]

DeCicca, P., D. Kenkel, and A. Mathios (2002), "Putting out the fires: Will higher taxes reduce the onset of youth smoking?" Journal of Political Economy, 110, 144-169. [825]

DeCicca, P., D. Kenkel, A. Mathios, Y.-J. Shin, and J.-Y. Lim (2008), "Youth smoking, cigarette prices, and anti-smoking sentiment.” Health Economics, 17, 733-749. [826]

DHHS (2012), "Preventing tobacco use among youth and young adults: A report of the surgeon general.” Atlanta, GA: US Department of Health and Human Services, Centers for Disease Control and Prevention, National Center for Chronic Disease Prevention and Health Promotion, Office on Smoking and Health, 2. [825, 828]

Digman, J. M. (1990), “Personality structure: Emergence of the five-factor model.” Annual Review of Psychology, 41, 417-440. [831]

Driscoll, A. K., S. T. Russell, and L. J. Crockett (2008), "Parenting styles and youth wellbeing across immigrant generations.” Journal of Family Issues, 29, 185-209. [833]

Eisenberg, D. (2004), "Peer effects for adolescent substance use: Do they really exist." UC-Berkeley School of Public Health working paper. [830]

Eisenberg, D., E. Golberstein, and J. L. Whitlock (2014), "Peer effects on risky behaviors: New evidence from college roommate assignments." Journal of Health Economics, 33, 126-138. [827, 830]

Fletcher, J. M. (2010), “Social interactions and smoking: Evidence using multiple student cohorts, instrumental variables, and school fixed effects." Health Economics, 19, 466484. [826, 830, 841]

Fletcher, J. M., P. Deb, and J. L. Sindelar (2009), Tobacco Use, Taxation and Self Control in Adolescence. Technical report, National Bureau of Economic Research Working Paper 15130. [831]

Fortin, B. and M. Yazbeck (2015), "Peer effects, fast food consumption and adolescent weight gain.” Journal of Health Economics (forthcoming). [837]

Fowler, J. H. and N. A. Christakis (2008), "Estimating peer effects on health in social networks: A response to Cohen-Cole and Fletcher; and Trogdon, nonnemaker, and pais." Journal of Health Economics, 27, 1400-1405. [830] 
Fruehwirth, J. C. (2014), "Can achievement peer effect estimates inform policy? A view from inside the black box." Review of Economics and Statistics, 96, 514-523. [826, 827, 828, 840, 856]

Gaviria, A. and S. Raphael (2001), "School-based peer effects and juvenile behavior.” Review of Economics and Statistics, 83, 257-268. [830, 841]

Geweke, J. (1992), "Evaluating the accuracy of sampling-based approaches to calculating posterior moments.” In Bayesian Statistics, Vol. 4 (J. M. Bernardo, M. J. Bayarri, J. O. Berger, A. P. Dawid, and A. F. M. Smith, eds.). Oxford University Press. [843, 845]

Girard, Y., F. Hett, and D. Schunk (2015), "How individual characteristics shape the structure of social networks." Journal of Economic Behavior \& Organization, 115, 197-216. $[835,856]$

Glaeser, E. L. and J. A. Scheinkman (2003), “Nonmarket interactions.” In Advances in Economics and Econometrics: Theory and Applications (M. Dewatripont, L. P. Hansen, and S. J. Turnovsky, eds.), 339-369, Cambridge University Press. [829]

Goldsmith-Pinkham, P. and G. W. Imbens (2013), "Social networks and the identification of peer effects.” Journal of Business \& Economic Statistics, 31, 253-264. [826, 827, 854]

Graham, B. S. (2015), “Methods of identification in social networks.” Annual Review of Economics (forthcoming). [826]

Graham, B. S., G. W. Imbens, and G. Ridder (2010), Measuring the Effects of Segregation in the Presence of Social Spillovers: A Nonparametric Approach. Technical report, National Bureau of Economic Research Working Paper w16499. [856]

Gul, F. and W. Pesendorfer (2004), "Self-control and the theory of consumption." Econometrica, 72, 119-158. [831]

Hampson, S. E., L. R. Goldberg, T. M. Vogt, and J. P. Dubanoski (2007), "Mechanisms by which childhood personality traits influence adult health status: Educational attainment and healthy behaviors." Health Psychology, 26, 121. [828]

Hampson, S. E., E. Tildesley, J. A. Andrews, K. Luyckx, and D. K. Mroczek (2010), “The relation of change in hostility and sociability during childhood to substance use in mid adolescence." Journal of Research in Personality, 44, 103-114. [828]

Heckman, J., R. Pinto, and P. Savelyev (2013), “Understanding the mechanisms through which an influential early childhood program boosted adult outcomes." American Economic Review, 103, 2052-2086. [826, 831]

Heckman, J. J. (2000), “Policies to foster human capital.” Research in Economics, 54, 3-56. $[831,856]$

Heckman, J. J., F. Flyer, and C. Loughlin (2008), "An assessment of causal inference in smoking initiation research and a framework for future research." Economic Inquiry, 46, 37-44. [825, 826] 
Heckman, J. J., J. Stixrud, and S. Urzua (2006), “The effects of cognitive and noncognitive abilities on labor market outcomes and social behavior." Journal of Labor Economics, 24, 411-482. [831, 833]

Hsieh, C.-S. and L.-F. Lee (2016), "A social interactions model with endogenous friendship formation and selectivity." Journal of Applied Econometrics, 31, 301-319. [826, 827, 837, 839, 840, 841, 846, 853, 854]

Kawaguchi, D. (2004), "Peer effects on substance use among American teenagers.” Journal of Population Economics, 17, 351-367. [830]

Kooreman, P. (2007), “Time, money, peers, and parents; some data and theories on teenage behavior.” Journal of Population Economics, 20, 9-33. [830]

Krauth, B. V. (2007), "Peer and selection effects on youth smoking in California.” Journal of Business \& Economic Statistics, 25, 288-298. [830, 841]

Lee, L.-F. (2007), "Identification and estimation of econometric models with group interactions, contextual factors and fixed effects." Journal of Econometrics, 140, 333-374. [827]

Lee, L.-F., X. Liu, and X. Lin (2010), "Specification and estimation of social interaction models with network structures.” Econometrics Journal, 13, 145-176. [827, 837]

Lin, X. (2010), "Identifying peer effects in student academic achievement by spatial autoregressive models with group unobservables." Journal of Labor Economics, 28, 825860. [827, 837]

Lin, X. and B. Weinberg (2014), "Unrequited friendship? How reciprocity mediates adolescent peer effects.” Regional Science and Urban Economics, 48, 144-153. [837]

Liu, X. (2013), "Estimation of a local-aggregate network model with sampled networks." Economics Letters, 118, 243-246. [852]

Liu, X., E. Patacchini, and Y. Zenou (2014), "Endogenous peer effects: Local aggregate or local average?” Journal of Economic Behavior \& Organization, 103, 39-59. [839]

Lundborg, P. (2006), "Having the wrong friends? Peer effects in adolescent substance use.” Journal of Health Economics, 25, 214-233. [830, 841]

Lyons, R. (2011), “The spread of evidence-poor medicine via flawed social-network analysis.” Statistics, Politics, and Policy, 2. [830]

Manski, C. F. (1993), "Identification of endogenous social effects: The reflection problem.” The Review of Economic Studies, 60, 531-542. [826, 836]

Matthews, G., I. J. Deary, and M. C. Whiteman (2003), Personality Traits. Cambridge University Press. [831]

Mendolia, S. and I. Walker (2014), "The effect of noncognitive traits on health behaviours in adolescense.” Health Economics, 23, 1146-1158. [831, 833] 
Moffitt, R. A. (2001), "Policy interventions, low-level equilibria, and social interactions." Social Dynamics, 4, 6-17. [826, 837]

Mokdad, A. H., J. S. Marks, D. F. Stroup, and J. L. Gerberding (2004), "Actual causes of death in the United States, 2000.” JAMA, 291, 1238-1245. [825]

Navarro, S. (2008), “Control functions.” The New Palgrave Dictionary of Economics. [839]

Norton, E. C., R. C. Lindrooth, and S. T. Ennett (1998), “Controlling for the endogeneity of peer substance use on adolescent alcohol and tobacco use.” Health Economics, 7, 439453. [830]

OECD (2013), "Health at a glance 2013: OECD indicators.” Organization of Economic Cooperation and Development. [825]

Powell, L. M., J. A. Tauras, and H. Ross (2005), “The importance of peer effects, cigarette prices and tobacco control policies for youth smoking behavior." Journal of Health Economics, 24, 950-968. [830, 841]

Raftery, A. E. and S. M. Lewis (1992), “How many iterations in the Gibbs sampler?” In Bayesian Statistics, Vol. 4 (J. M. Bernardo, M. J. Bayarri, J. O. Berger, A. P. Dawid, and A. F. M. Smith, eds.). Oxford University Press. [843, 845]

Raftery, A. E., M. A. Newton, J. M. Satagopan, and P. N. Krivitsky (2007), "Estimating the integrated likelihood via posterior simulation using the harmonic mean identity." In Bayesian Statistics, Vol. 8 (J. M. Bernardo, M. J. Bayarri, J. O. Berger, A. P. Dawid, D. Heckerman, A. F. M. Smith, and M. West, eds.), 1-45, Oxford University Press. [844]

Sacerdote, B. (2001), "Peer effects with random assignment: Results for Dartmouth roommates.” The Quarterly Journal of Economics, 116, 681-704. [827]

Sacerdote, B. (2011), "Peer effects in education: How might they work, how big are they and how much do we know thus far?" Handbook of the Economics of Education, 3, 249277. [827, 829]

Savelyev, P. A. (2014), Socioemotional Skills, Education, and Longevity of High-Ability Individuals. Technical report. Available at SSRN http://ssrn.com/abstract=1715942. [833]

Shakya, H. B., N. A. Christakis, and J. H. Fowler (2012), "Parental influence on substance use in adolescent social networks." Archives of Pediatrics \& Adolescent Medicine, 166, 1132-1139. [833]

Soetevent, A. R. and P. Kooreman (2007), "A discrete-choice model with social interactions: With an application to high school teen behavior." Journal of Applied Econometrics, 22, 599-624. [830]

VanderWeele, T. J., E. L. Ogburn, and E. J. Tchetgen Tchetgen (2012), "Why and when 'Flawed' social network analyses still yield valid tests of no contagion." Statistics, Politics, and Policy, 3. [830] 
Young, J. K. and A. A. Beaujean (2011), "Measuring personality in wave I of the national longitudinal study of adolescent health." Frontiers in Psychology, 2. [826, 833]

Zeger, S. L. and M. R. Karim (1991), "Generalized linear models with random effects; a Gibbs sampling approach." Journal of the American Statistical Association, 86, 79-86. [841]

Zimmerman, D. J. (2003), "Peer effects in academic outcomes: Evidence from a natural experiment.” Review of Economics and Statistics, 85, 9-23. [827]

Co-editor Petra E. Todd handled this manuscript.

Manuscript received 16 September, 2015; final version accepted 15 August, 2017; available online 22 September, 2017. 